\title{
EVOLUTIONARY ALGORITHMS FOR OPTIMUM DESIGN OF THIN BROADBAND MULTILAYER MICROWAVE ABSORBER
}

\author{
Jyotirmay Tewary ${ }^{1}$, G. K. Mahanti ${ }^{2}$, Kajla Basu ${ }^{3}$ \\ ${ }^{1}$ Assistant Professor, Department of Electronics \& Communication Engineering, Bengal college of Engineering \& \\ Technology Durgapur, West Bengal, India \\ ${ }^{2}$ Professor, Department of Electronics \& Communication Engineering, National Institute of Technology Durgapur, \\ West Bengal, India \\ ${ }^{3}$ Professor, Department of Mathematics, National Institute of Technology Durgapur, West Bengal, India
}

\begin{abstract}
In this paper we focused on the comparative study of three very popular and most recently developed nature inspired evolutionary algorithms namely Biogeography based optimization algorithm (BBO), Flower pollination algorithm (FPA) and Artificial bee colony optimization algorithm (ABC) for developing a model of 6 layers thin broadband (0.2-20GHz) microwave absorber. The model is optimized for oblique wide angle of incidence $\left(45^{\circ}, 60^{\circ}\right)$ taking both TE and TM polarization of the electromagnetic wave under consideration. The primary goal of our design is to minimizing the overall reflection coefficient of the absorber and its total thickness by selecting the proper layer of materials from a predefined database of existing materials. 8 different models are presented and synthesize considering both these design consideration simultaneously and for only overall reflection coefficient of the absorber while total thickness is not taken into consideration during optimization for each cases. The optimum values of all the significant parameters of the multilayer absorber for different models have been compared and tabulated using BBO, FPA and $A B C$ algorithms which established the superiority of our proposed design.
\end{abstract}

Keywords: Multilayer microwave absorber, Oblique incidence, Broadband, Evolutionary algorithms, Arbitrary polarization

\section{INTRODUCTION}

Microwave Absorbers in the RF/Microwave Engineering are the material that is widely used to attenuate energy in an Electromagnetic wave. This Absorber is capable to reduce electromagnetic hazards or unwanted radiation that could interfere with the system operation and may degrade the performance of the system as well. To avoid this unwanted or undesired interference instruments and other devices are coated or protected by absorbing materials. This make the multilayer microwave absorber finds its wide range of application in almost all defense and civil electronics industries like radar systems, satellite communication, electromagnetic compatibility and many more. So with the increasing applications of this microwave absorber in this modern age of electronics inspire engineers to take this problem of developing optimum design of multilayer microwave absorber as a challenging task. While designing the same we have to consider some fact which is inherently conflicting in nature. The absorber must have minimum reflecting coefficient of the electromagnetic wave in a particular frequency band and incident angle for arbitrary polarization of the electromagnetic wave as well as the absorber should be thin and lightweight too. So there must be a proper trade-offs between all these conflicting goals. This can be achieve only by adjusting different parameters of the multilayer structure of the microwave absorber such as number of layers, permeability, permittivity, frequency range, the angle of incidence, thickness of the individual layers, types of material used and the wave polarization using different optimization technique. Earlier some older optimization algorithm like simplex method, simulated annealing was implemented for the design of multilayer microwave absorber but they finds their limitations to have a large convergence time and a tendency to get trapped in local optimization[13]. Hence more modified and sophisticated evolutionary algorithm such as Genetic algorithm (GA) [1-3, 6], Central force optimization (CFO) [7], Differential evolution (DE) [8] and particle swarm optimization (PSO) [4, 5, 14-22], have been applied more successfully to the problem of design of multilayer microwave absorber. In this paper a comparative study of comparatively newly developed nature inspired optimization algorithms such as Biogeography based optimization algorithm (BBO) [23-25], Flower pollination algorithm (FPA) [26]and Artificial bee colony optimization algorithm(ABC)[27-28], have been successfully implemented for the optimum design of 6 layers microwave absorber. The absorber is optimized for oblique wide angle of incidence $\left(45^{\circ}, 60^{\circ}\right)$ in the wide frequency band $(0.2$ $20 \mathrm{GHz}$ ) considering both TE and TM polarization of the electromagnetic wave. While formulating the objective or cost function we included the weighted form of the total thickness along with the reflection coefficient to solve the conflicting parameters of our design more significantly. A brief overview for the remainder of this paper is as follows: Section 2 gives the basic concept of multilayer structure of the microwave absorber, section 3 explain the formulation 
of the cost function to be optimized using evolutionary algorithms, the fundamental concept and theoretical overview of BBO, FPA and ABC algorithms are described in the section 4 , the simulation results and significant parameters of different models of the multilayer microwave absorber of our design is presented in section 5 and finally the concluding arguments are explained in section 6 respectively.

\section{PHYSICAL ELECTROMAGNETIC MODEL}

\section{OF MULTILAYER MICROWAVE ABSORBER}

The generalized multilayer electromagnetic model of a microwave absorber consists of $\mathrm{N}$ number of layers of different materials with frequency dependent permittivity and permeability available from a specific predefined material database. This is backed by perfect electric conductor (PEC) which acts as a perfect reflection backing and consider as the last layer of the model (layer number $\mathrm{N}+1$ ). The electromagnetic wave of a specific frequency travel through air (free space) which is consider as a layer number 0 and incident obliquely to the first surface of the multilayer structure making an incident angle $\theta$ with the normal ( $\mathrm{z}$ axis) at the point of incidence. This is illustrated in Fig.1.Now the generalized reflection coefficient between any two layers of the multilayer structure of the microwave absorber can be evaluate from the concept of transmission line theory[9], using the following algorithm:

$$
\boldsymbol{R}_{i, i+1}=\frac{\rho_{i, i+1}+R_{i+1, i+2} \exp \left(-2 j k_{i+1} d_{i+1}\right)}{1+\rho_{i, i+1} R_{i+1, i+2} \exp \left(-2 j k_{i+1} d_{i+1}\right)}
$$

Where,

For TM (parallel) polarization:

$$
\rho_{i, i+1}=\frac{\varepsilon_{i+1} k_{i}-\varepsilon_{i} k_{i+1}}{\varepsilon_{i+1} k_{i}+\varepsilon_{i} k_{i+1}} i<N
$$

For TE (perpendicular) polarization:

$$
\rho_{i, i+1}=\frac{\mu_{i+1} k_{i}-\mu_{i} k_{i+1}}{\mu_{i+1} k_{i}+\mu_{i} k_{i+1}} i<N
$$

In the above equations,

$\varepsilon_{i}=$ frequency dependent complex permittivity of $\mathrm{i}^{\text {th }}$ layer.

$\mu_{i}=$ frequency dependent complex permeability of $\mathrm{i}^{\text {th }}$ layer.

$k_{i}=$ wave number of the $\mathrm{i}^{\text {th }}$ layer and according to Snell's law it is related with the incident angle $\theta$ as follows:

$$
k_{i}=\omega \sqrt{\mu_{i} \varepsilon_{i}-\mu_{0} \varepsilon_{0} \sin ^{2}(\theta)}
$$

In equation (4), $\omega$ represents the frequency of the incident wave whereas $\varepsilon_{0}$ and $\mu_{0}$ denote the permittivity and permeability of free space respectively, i.e.

$$
\begin{aligned}
& \varepsilon_{0}=8.854 * 10^{-12} \frac{F}{m} \\
& \mu_{0}=4 \pi * 10^{-7} \frac{H}{m}
\end{aligned}
$$

In this paper the most important fact regarding the design of multilayer structure of the microwave absorber we have taken into consideration is that for normal incidence of the electromagnetic wave both TE and TM polarizations yield the same magnitude of the reflection coefficient [8] and set the reflection coefficient between the last layer of the multilayer structure and the PEC $\left(\boldsymbol{R}_{N, N+1}\right)$ to +1 for TM polarization where as it set to -1 for TE polarization of the electromagnetic wave. This seems to be neglected in many papers [10,11,12], deals with the same problem and wrongfully set to -1 for both TE and TM polarizations, results in different values for the magnitude of the reflection coefficient for normal incidence but which is not the case actually. From this above consideration the overall reflection coefficient of the multilayer absorber is now computed recursively using the equations (1)-(6).

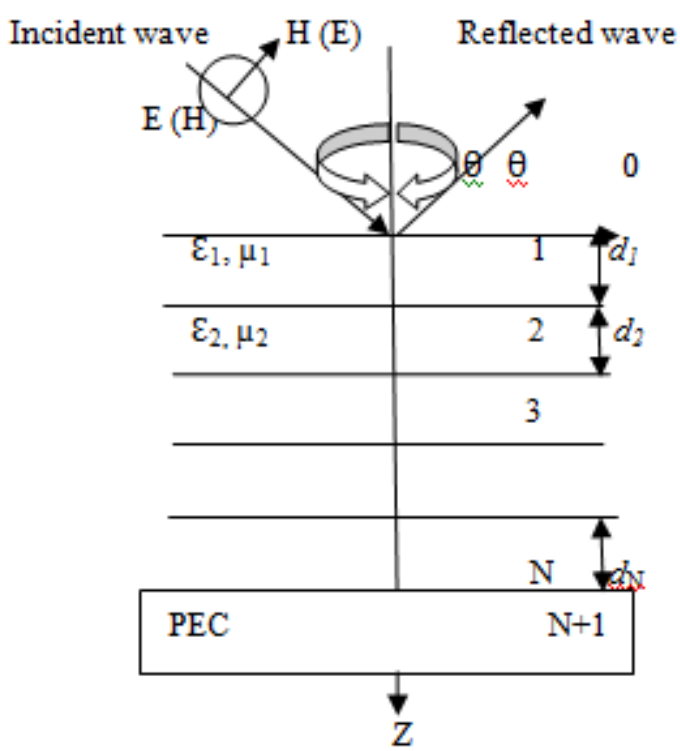

Fig -1: Physical model of multilayer microwave absorber

\section{THE FITNESS FUNCTION}

In this paper we mainly concentrate on the fact to find out the particular set of materials with frequency dependent permittivity and permeability available from a predefined database of existing materials to minimize the overall reflection coefficient of the multilayer microwave absorber. The simulation is carried out for a particular frequency band, wave polarization and angle of incidence. While designing the same it is also desired that the thickness of the multilayer structure should be least practically possible. Therefore both these design requirement are taken into consideration in the form of following fitness function:

$\operatorname{minimum} F=K_{1} * 20 \log _{10}\left(\max \left(\left|R_{0,1}\right|\right)\right)+K_{2} \sum_{i=1}^{N} d_{i}$ 
Where along with the weighted sum of overall maximum reflection coefficient of the multilayer microwave absorber, the sum of all the individual layer thickness in meters is also consider for optimization as well which makes our proposed model more attractive in its grade. In the objective function (7) $K_{1}, K_{2}$ are weighting constants emphasizing each of the term associated with the fitness function and has been set to $K_{l}=1$ and $K_{2}=1000$ respectively for all cases.

\section{ALGORITHM OVERVIEWS}

\subsection{Overview of BBO Algorithm}

BBO algorithm is a population based search technique having faster convergence rates. The basic concept of this algorithm was first introduced by Dan Simon in 2008 motivated and influenced by the biological organism distribution in time and space.

The steps evolved in BBO algorithm are as follows:

Step1: The BBO parameters like initialization of the maximum species count, maximum rate of migration, maximum rate of mutation, elitism parameter are initialized.

Step 2: The suitability index variable (SIV) of each island which determine the potential solution to the given problem are generate randomly.

Step 3: The SIV for each island is evaluated

Step 4: The number of elite islands that have highest suitability index are identified

Step 5: Migration are performed probabilistically on those SIVs of non-elite islands based on the probabilistic model where $P_{S}(t)$ changes from time $t$ to time $t+\Delta t$ according to the following relation:

$P_{S}(\mathrm{t}+\Delta \mathrm{t})=P_{S}(t)\left(1-\lambda_{S} \Delta \mathrm{t}-\mu_{\mathrm{S}} \Delta \mathrm{t}\right)+P_{S-1}(t) \lambda_{S-1} \Delta \mathrm{t}+P_{S+1}$ (t) $\mu_{S+1} \Delta \mathrm{t}$

Where,

$\lambda_{S}($ immigration rate $)=I\left(1-\frac{S}{S \max }\right)$

$\mu_{S}$ (emigration rate) $=\frac{E S}{S \max }$

$S=$ Number of species in the habitat

Smax $=$ maximum number of species supported by the habitat

$I=$ Maximum immigration rate

$P_{S}(t)=$ probability of the habitat

$E$ = Maximum possible value of emigration rate

Step 6: Mutation operation is performed probabilistically on those non-elite islands based on the mutation probability as: $m(S)=m_{\max }\left(\frac{1-p_{s}}{p_{\max }}\right)$

Where,

$m(S) \quad=$ Mutation rate for habitat having $S$ species

$m_{\max }=$ Maximum mutation rate

$p_{\max }=$ Mmaximum probability

Step 7: Repeat from steps 3 to 7 till the maximum number of iterations reaches.

Figure below shows the species model of a single habitat for $\mathrm{BBO}$ algorithm

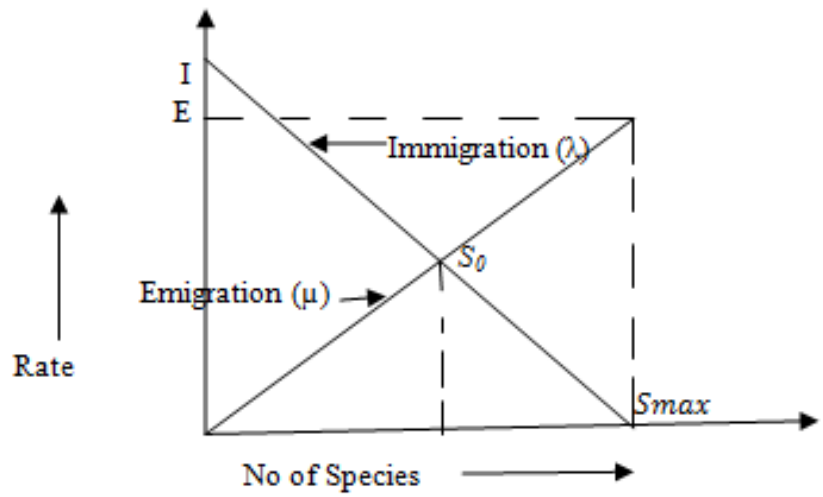

Fig -2: Species model of a single habitat

\subsection{Overview of FPA Algorithm}

Flower pollination algorithm is most recently developed nature inspired optimization algorithm. The concept was first developed by Xin-She Yang in the year 2012.The basic concept of this algorithm is based on the flower pollination process where the pollination process carried out by the varieties of pollinators like insects, bats, birds etc. In this process the pollen from the male parts of a flower is carried away to the female part called stigma of a flower by the pollinator. Basically the pollination process is classified into two categories, Biotic pollination process and Abiotic pollination process. Insects and animals are acts as a pollinator in case of Biotic pollination process whereas in Abiotic pollination, pollination occurs through wind or diffusion in water.

The steps evolved in Flower pollination algorithm are as follows:

Step1: The population of $\mathrm{n}$ flowers/pollen gametes is initialized randomly

Step2: The best solution $g_{*}$ is determined in the initial population

Step3: Switch probability $p \epsilon[0,1]$ is defined

Step4: while ( $t<$ Max Generation)

for $i=1$ to $n$ (all $n$ flowers/pollen in the population)

Step5: if rand $<p, d$-dimensional step vector $L$ is drawn which satisfied $L$ ' evy distribution

Global pollination via $x_{i}^{t+1}=x_{i}^{t}+L\left(g_{*}-x_{i}^{t}\right)$

Else

Draw $\epsilon$ from a uniform distribution in $[0,1]$

Local pollination via $x_{i}^{t+1}=x_{i}^{t}+\epsilon\left(x_{j}^{t}+x_{k}^{t}\right)$

End if

Step6: The new solutions are evaluated and updated them in the population if they are found better.

Step7: end for

Step8: the current best solution $g_{*}$ is find out

Step9: end while

\subsection{Overview of ABC Algorithm}

The concept of $\mathrm{ABC}$ algorithm was first developed by Basturk and Karaboga .This is also a very popular nature inspired swarm based optimization algorithm .It consist of three groups of bees known as employed bees, onlookers and scouts. The searching ability of this algorithm is 
completely depends on the various behavior of these three groups of bees. The positions of the food sources around a colony of artificial bees give the solutions of an optimization problem.

The steps evolved in Artificial bee colony optimization algorithms are as follows:

Step1: Initialize ' $n$ ' number of food positions or solutions randomly in the ' $\mathrm{d}$ ' dimensional search space as $: x_{i}=\left[x_{i 1}, x_{i 2}\right.$, $\left.\ldots \ldots, x_{i d}\right]$ where $i=1,2, \ldots \ldots, n$.

Step2: Evaluate objective function as per the relation:

fit $_{i}=\left\{1 / 1+f_{i}\right.$, if $\left.f_{i} \geq 0\right\}$,

fit $_{i}=\left\{1+a b s\left(f_{i}\right)\right.$, if $\left.f_{i}<0\right\}$ where $f_{i}=$ value of the objective function corresponding to $i_{\text {th }}$ solution.

Step3: The employed bees generated new solutions according to the relation given as:

$v_{i j}=x_{i j}+\operatorname{rand}_{i j}\left(x_{i j}-x_{k j}\right)$ where

$v_{i j}=$ modified position of $i_{t h}$ food source at $j_{t h}$ dimension rand $=$ random number, $k \quad\{1,2, \ldots \ldots, n\}$ and $j \quad\{1,2, . ., D\}$.

Step4: Evaluate new solutions and greedy selections are applied.

Step5: Based on computed probability factor $p_{i}$ the onlooker bees modify positions of some selected food sources (solutions) and greedy selection are applied, where pi $=\frac{\text { fit }_{i}}{\sum_{m=1}^{n} f_{i} t_{m}}$

Step6: The solution which is generated by scout bee replaced the abandoned solution in the population.

Step7: Record the best solution $\left(g_{\text {best }}\right)$ and its corresponding fitness (global fitness) value.

Step8: Repeat from steps 3 to 7 till the maximum number of iterations reaches.

Table -1: Predefined Database of Existing Materials [7, 8]

\begin{tabular}{|c|c|}
\hline \multicolumn{2}{|c|}{ Lossless dielectric material $\left(\mu_{r}=1+\mathrm{j} 0\right)$} \\
\hline \# & $\varepsilon_{\mathrm{r}}$ \\
\hline 1 & $10+\mathrm{j} 0$ \\
\hline 2 & $50+\mathrm{j} 0$ \\
\hline
\end{tabular}

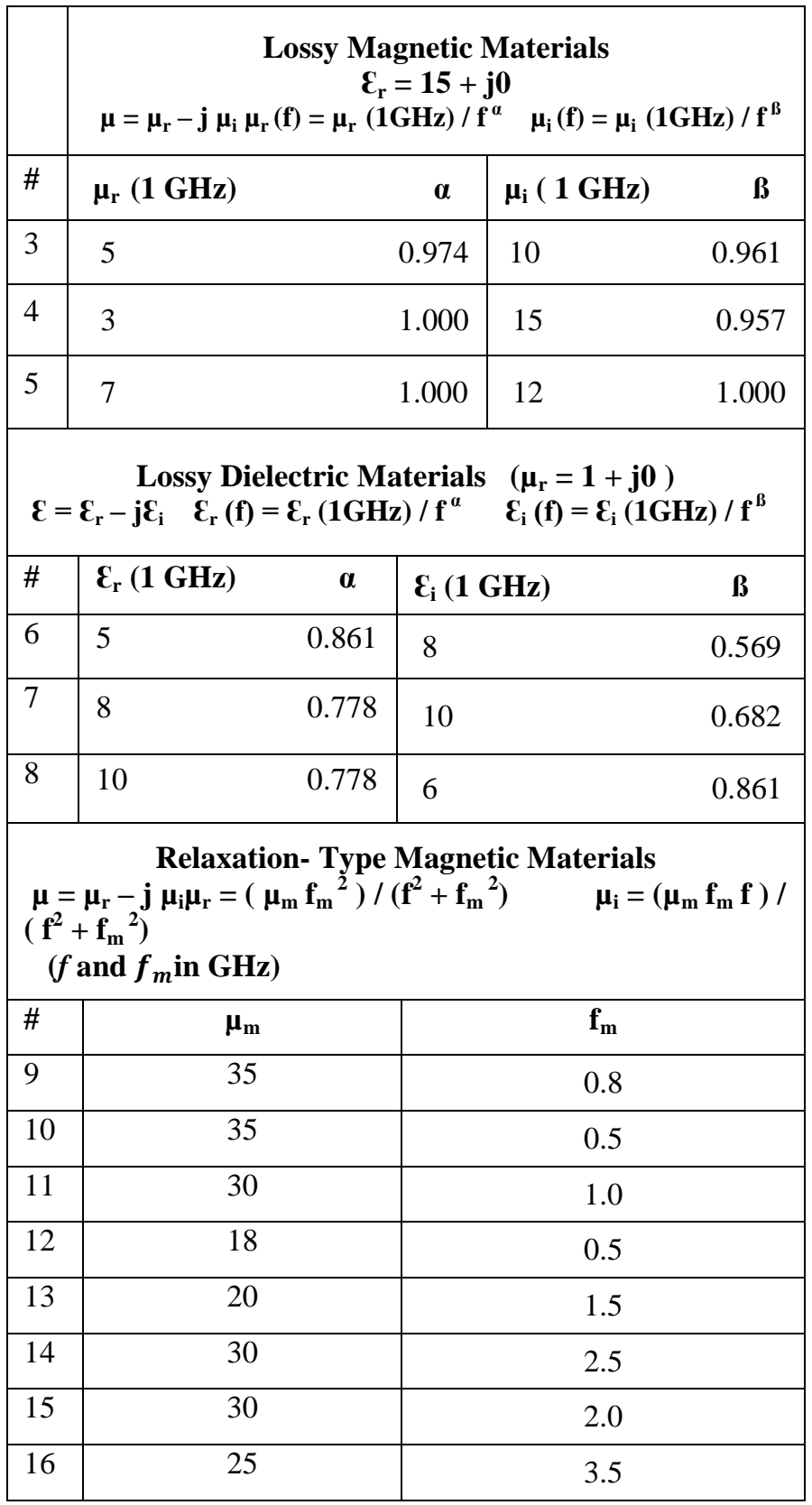

Table -2: Parametric setup of the BBO, FPA and ABC algorithms

\begin{tabular}{|c|c|c|c|c|c|}
\hline \multicolumn{2}{|l|}{ BBO } & \multicolumn{2}{|l|}{ FPA } & \multicolumn{2}{|l|}{$\mathbf{A B C}$} \\
\hline Parameters & Values & Parameters & Values & Parameters & Values \\
\hline Population size & 50 & Population size & 50 & colony size (NP) & 50 \\
\hline Number of elites & $\begin{array}{l}1 \text { (for model } \\
1,2,5,6,7,8)\end{array}$ & Probability switch & 0.8 & $\begin{array}{l}\text { Limit for } \\
\text { abandonment }\end{array}$ & 5 \\
\hline Number of elites & $2($ for model 3,4$)$ & Mutation probability & $3 / d$ & Food number & $\mathrm{NP} / 2$ \\
\hline $\begin{array}{l}\text { Search space } \\
\text { dimension }\end{array}$ & 12 & $\begin{array}{l}\text { Search space dimension } \\
\text { (d) }\end{array}$ & 12 & $\begin{array}{l}\text { Search space } \\
\text { dimension }\end{array}$ & 12 \\
\hline Run no & 20 & Run no & 20 & Run no & 20 \\
\hline $\begin{array}{l}\text { Termination } \\
\text { condition }\end{array}$ & $\begin{array}{l}1000 \text { iterations } \\
\max \end{array}$ & Termination condition & $\begin{array}{l}1000 \text { iterations } \\
\max \end{array}$ & $\begin{array}{l}\text { Termination } \\
\text { condition }\end{array}$ & $\begin{array}{l}1000 \\
\text { iterations } \\
\max \end{array}$ \\
\hline
\end{tabular}




\section{SIMULATION RESULTS}

The optimum results for the design of multilayer microwave absorber using three very popular and newly developed optimization algorithms Biogeography based optimization algorithm (BBO), Flower pollination algorithm (FPA) and Artificial bee colony optimization algorithm $(\mathrm{ABC})$ are presented in this section. The absorbers are design for wide range of frequencies $(0.2-20 \mathrm{GHz})$ with a frequency increase of $0.1 \mathrm{GHz}$ at each step. 8 different models are optimized for oblique wide angle of incidence $\left(45^{\circ}, 60^{\circ}\right)$ taking both TE and TM polarization of electromagnetic wave under consideration. The models are optimized taking overall reflection coefficient and total thickness of the absorber simultaneously and only for overall reflection coefficient of the microwave absorber while total thickness is not taken into consideration for each cases named as model1 ( optimized for oblique incidence, $45^{\circ}$ TE polarization considering overall reflection coefficient and total thickness of the absorber simultaneously),model2(optimized for oblique incidence, $45^{0}$ TE polarization considering only overall reflection coefficient of the absorber, total thickness is not taken into consideration),model3(optimized for $45^{\circ}$, TM polarization considering overall reflection coefficient and total thickness of the absorber at the same time), model4(optimized for $45^{\circ}$, TM polarization considering overall reflection coefficient while overall thickness is not considered here), model5 $\left(60^{\circ}\right.$ TE polarization, overall reflection coefficient and total thickness is optimized simultaneously), model6 $6\left(60^{\circ}\right.$,TE polarization optimized for overall reflection coefficient of the absorber and total thickness of the absorber is not taken into consideration), model7(optimized for $60^{\circ} \mathrm{TM}$ polarization and taken both overall reflection coefficient and total thickness of the absorber into consideration), model8(optimized for $60^{\circ} \mathrm{TM}$ polarization and overall reflection coefficient of the absorber, total thickness is not consider here for optimization).It has been observed that for model1 BBO gives better frequency response over the desired band of frequency while FPA results in thinner absorber design as compare to all other algorithms. In case of model 2 again BBO comes out with better frequency response over all other algorithms while FPA is the better choice for thinner absorber design among all other algorithms. For model 3 it has been found that the frequency response of $\mathrm{BBO}$ over the desired frequency band is much better as compare to all other algorithms but for thinner absorber design $\mathrm{ABC}$ is the better option. Similarly for model4 $\mathrm{BBO}$ gives better frequency response and FPA results in slightly thinner absorber design as compare to all other algorithms. In case of model5 FPA performed slightly better frequency response while BBO results in slightly thinner absorber design as compare to all other algorithms. For model6 it has been observed that the frequency response of BBO is slightly superior over the desired frequency band while $\mathrm{ABC}$ results in slightly thinner absorber design among all other algorithms. Similarly in case of model7 again it has been found that the frequency response of $\mathrm{BBO}$ is much better over all other algorithms but regarding the thinner absorber design FPA is the better choice and finally for model8 it has been observed that BBO comes out with clear winner in all relevant aspects over all other algorithms. The simulated optimum results and their parametric and statistical comparison for each models has been presented in table $3,4,5.6,7,8,9,10,11,12,13,14,15,16,17$ and 18 respectively for convenience. The frequency response and the variation of mean of gbest value with iterations for all the above models are presented in (figure 3-figure10) and (figure 11- figure 18) respectively. For simulation all the three algorithms are run for 20 independent trials and each time the maximum number of iterations is set to 1000 .

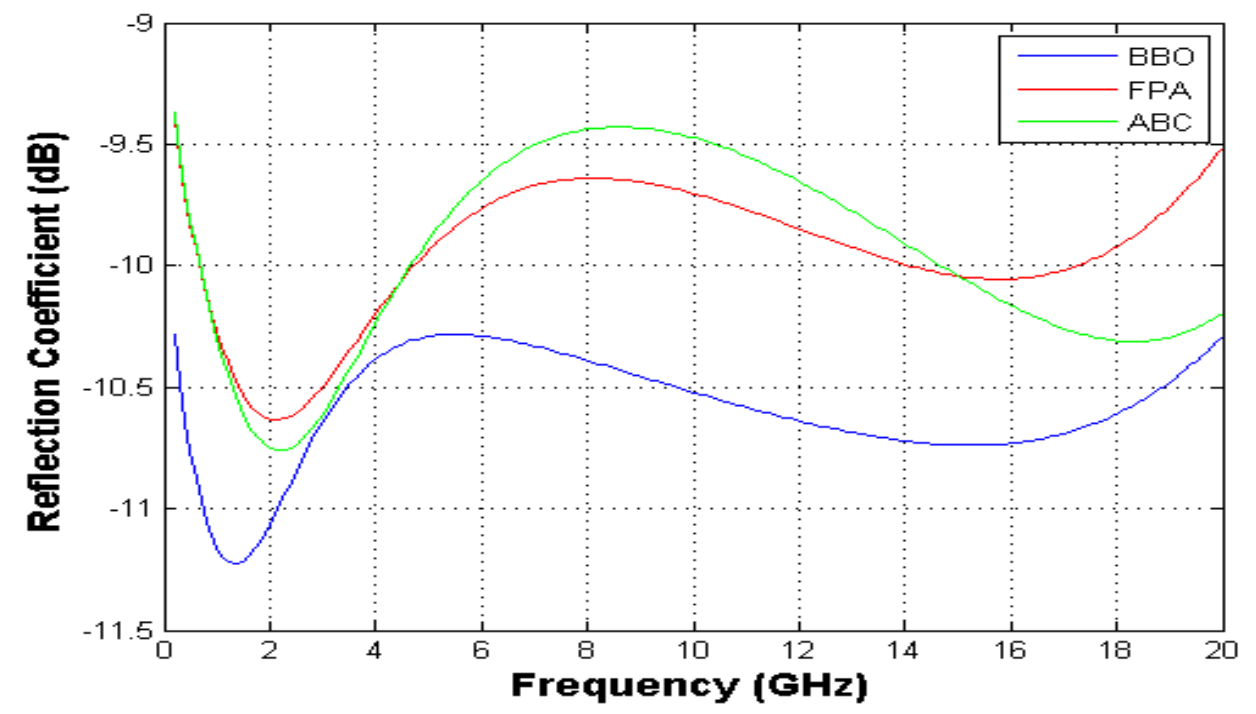

Fig -3: Reflection coefficient versus frequency (Model 1) 


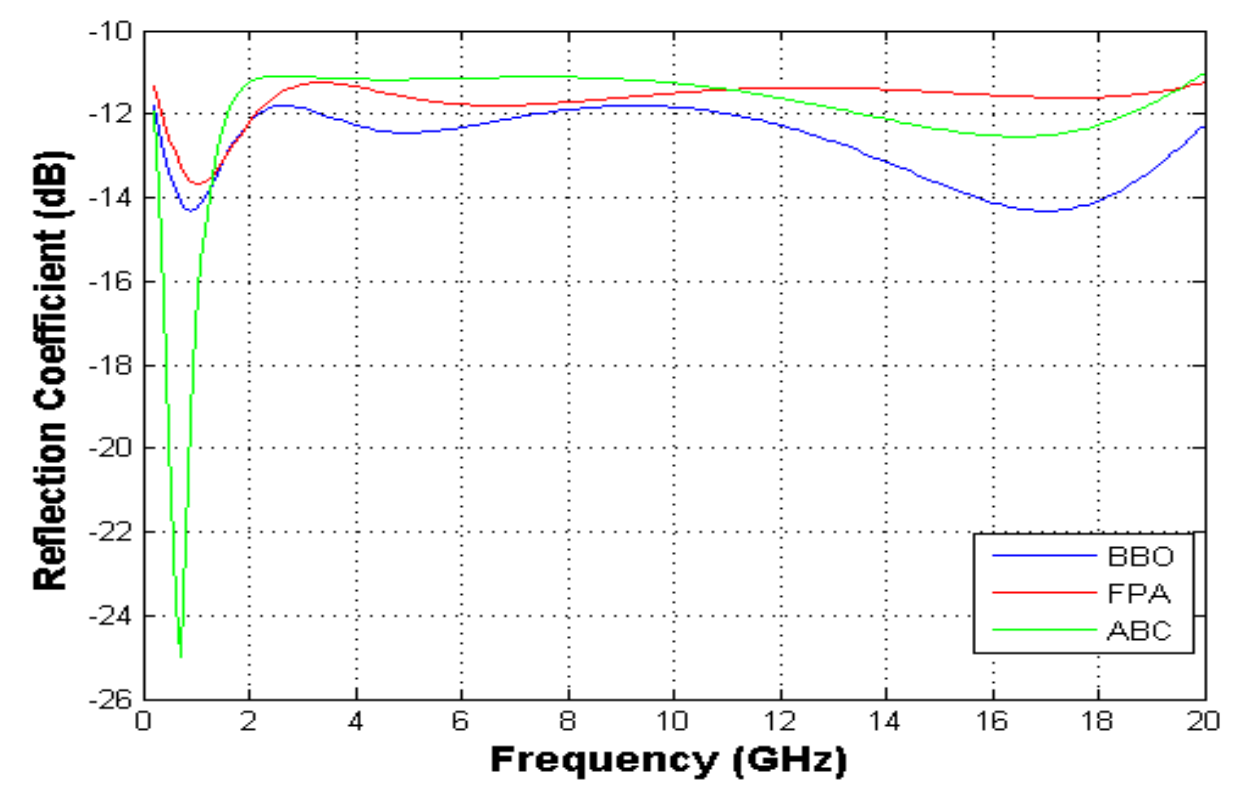

Fig -4: Reflection coefficient versus frequency (Model 2)

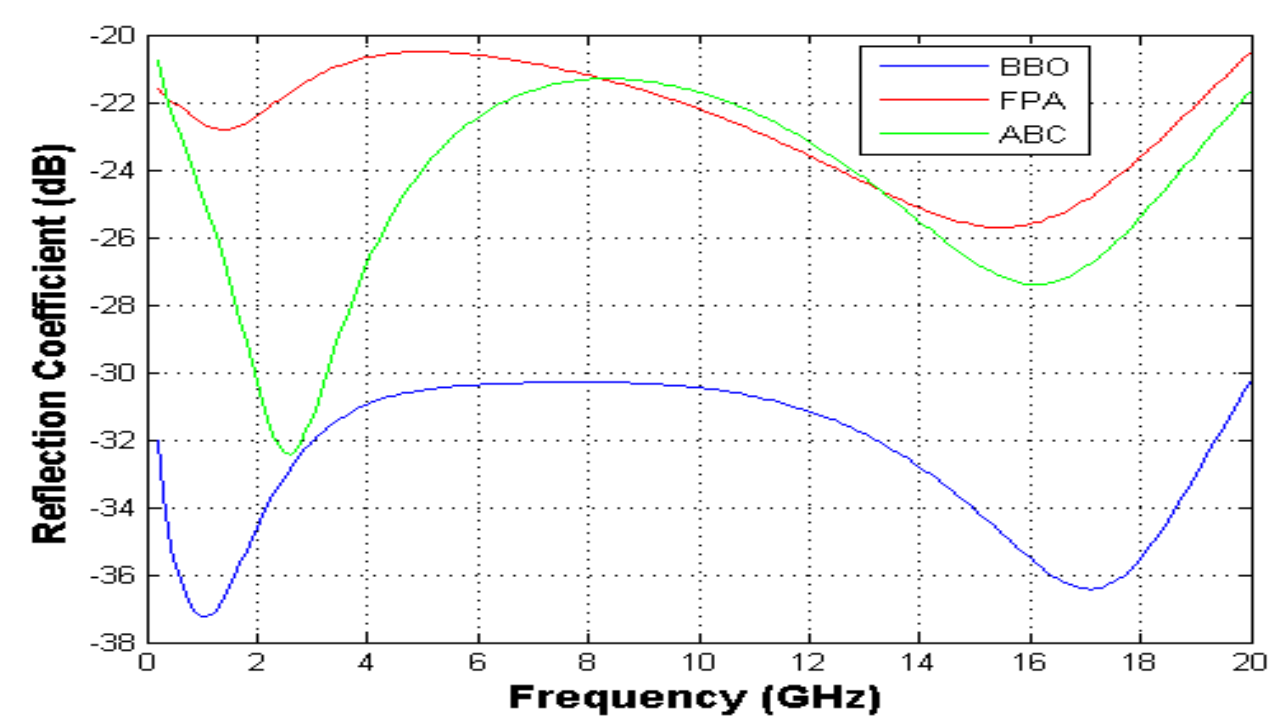

Fig -5: Reflection coefficient versus frequency (Model 3)

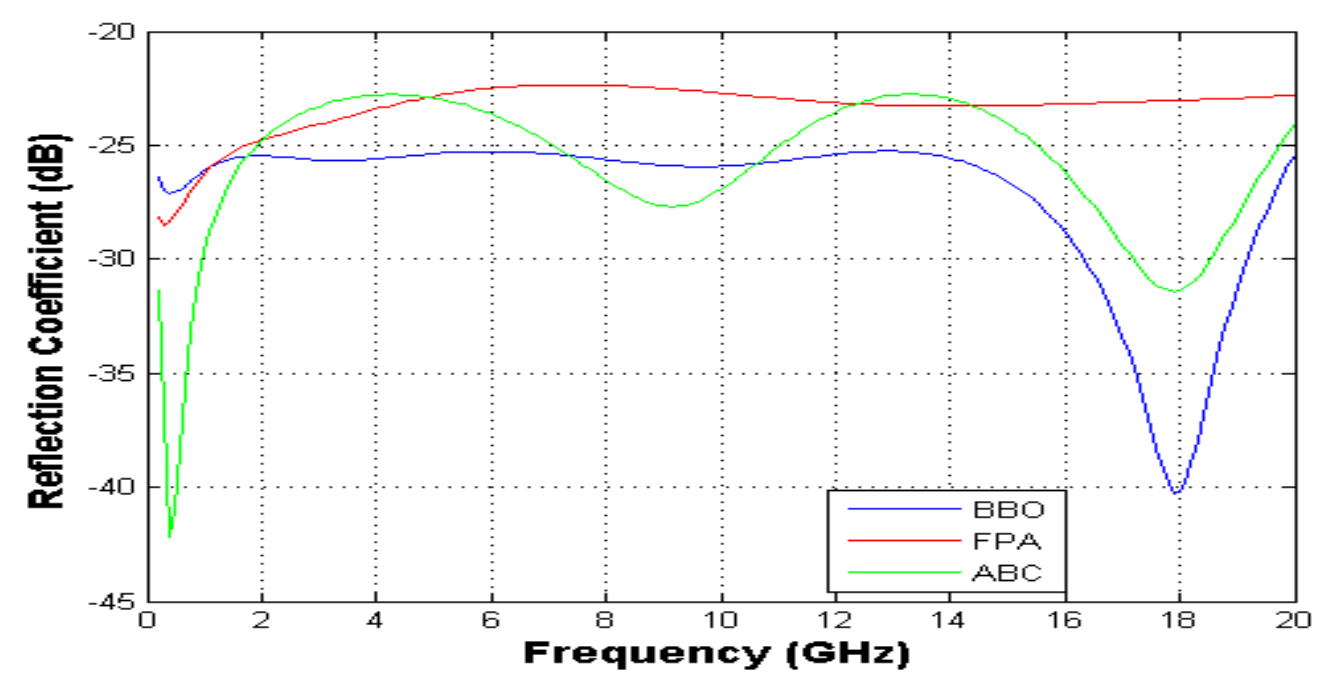

Fig -6: Reflection coefficient versus frequency (Model 4) 


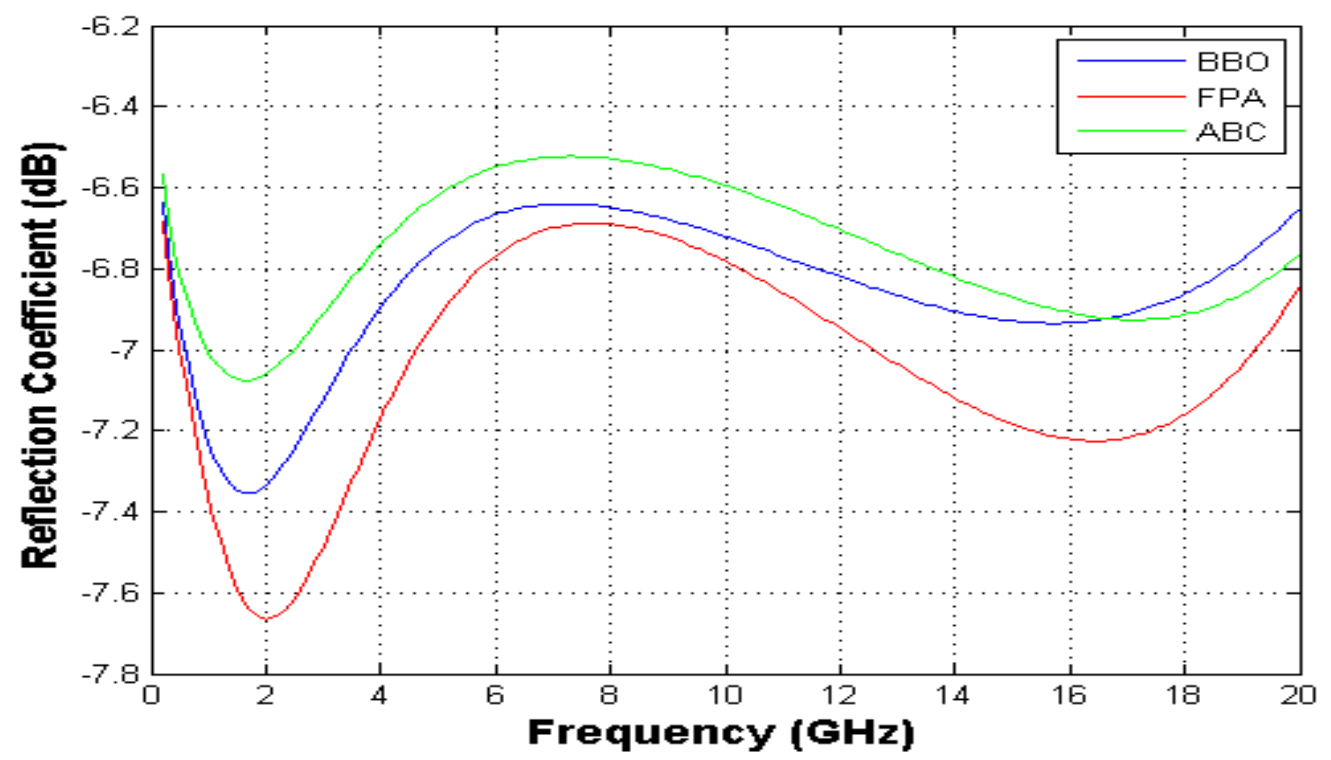

Fig -7: Reflection coefficient versus frequency (Model 5)

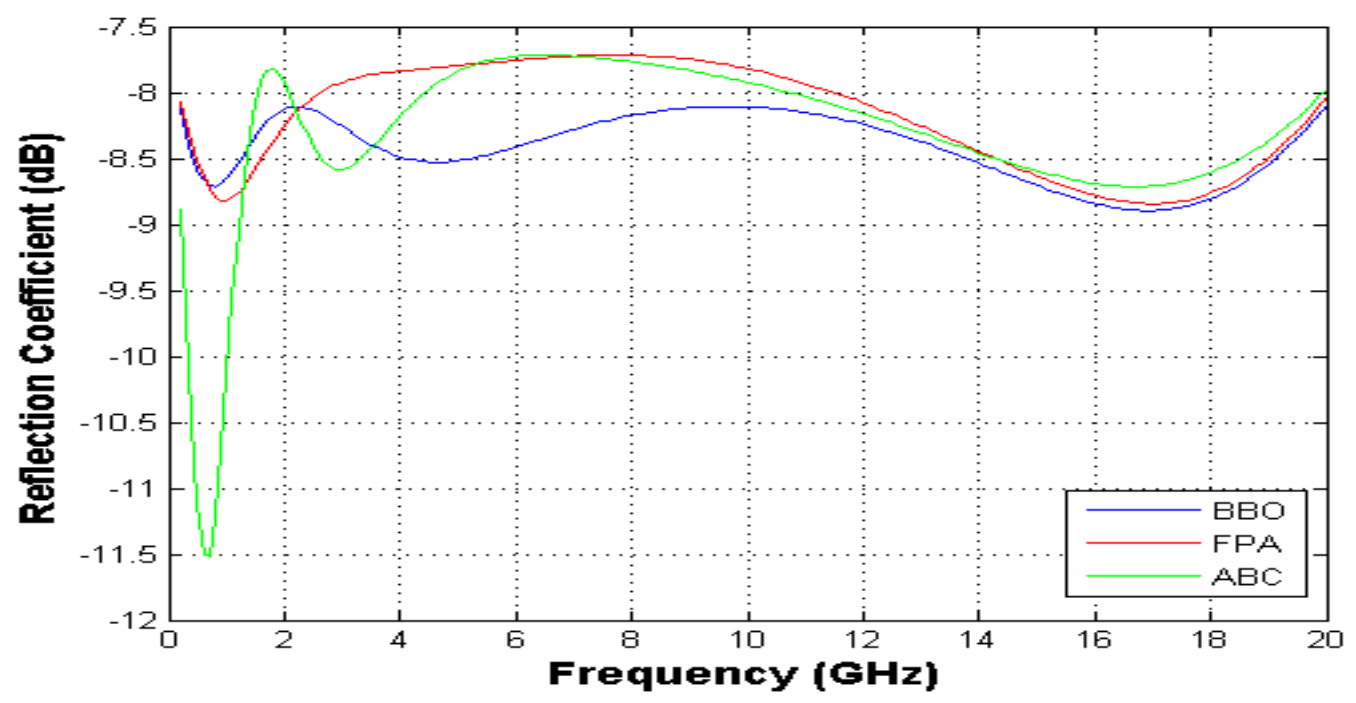

Fig -8: Reflection coefficient versus frequency (Model 6)

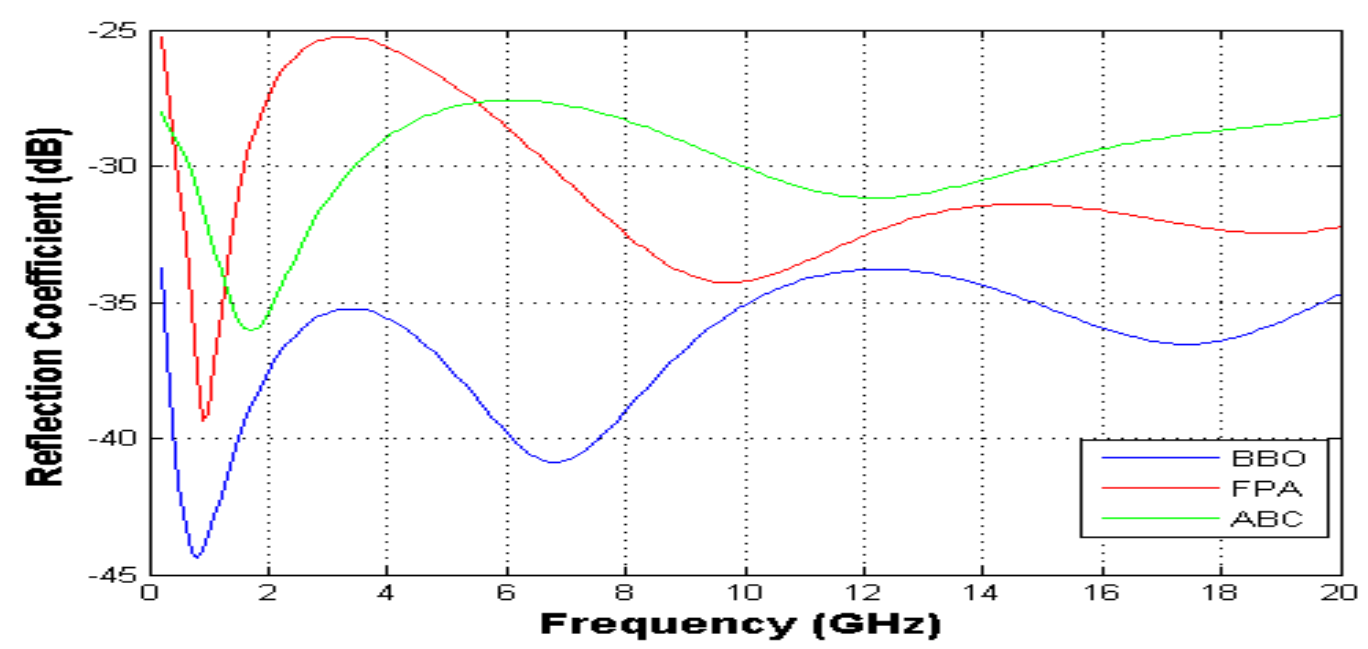

Fig -9: Reflection coefficient versus frequency (Model 7) 


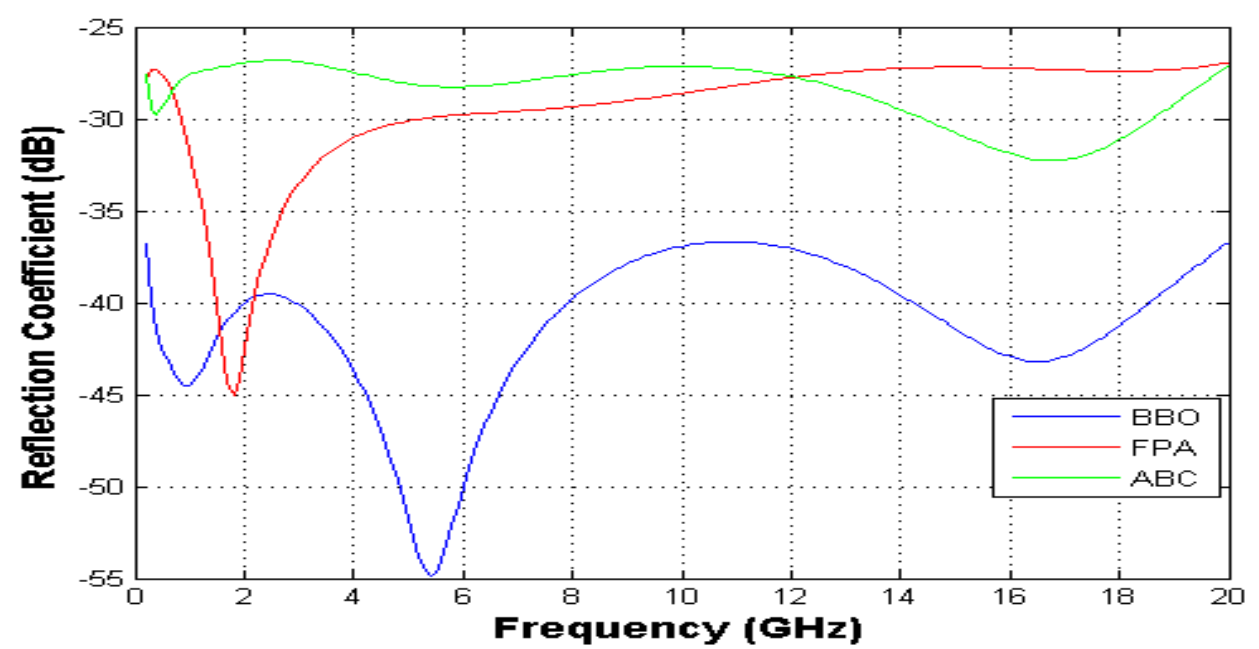

Fig -10: Reflection coefficient versus frequency (Model 8)

Table -3: Parameters for microwave absorber (6 layers) design for oblique incidence $\left(45^{0}\right)$ TE polarization optimized for overall reflection coefficient and total thickness of the absorber (Model 1)

\begin{tabular}{|c|c|c|c|c|c|c|}
\hline \multirow[b]{2}{*}{ Layer } & \multicolumn{2}{|l|}{ BBO } & \multicolumn{2}{|l|}{ FPA } & \multicolumn{2}{|l|}{$\mathrm{ABC}$} \\
\hline & $\begin{array}{l}\text { Material } \\
\text { No. }\end{array}$ & $\begin{array}{l}\text { Thickness in } \\
\text { mm }\end{array}$ & $\begin{array}{l}\text { Material } \\
\text { No. }\end{array}$ & $\begin{array}{l}\text { Thickness in } \\
\text { mm }\end{array}$ & $\begin{array}{l}\text { Material } \\
\text { No. }\end{array}$ & $\begin{array}{l}\text { Thickness in } \\
\text { mm }\end{array}$ \\
\hline 1 & 16 & 0.2490 & 16 & 0.3131 & 16 & 0.2949 \\
\hline 2 & 6 & 1.0680 & 6 & 0.7610 & 6 & 0.9064 \\
\hline 3 & 14 & 0.1820 & 5 & 0.3094 & 4 & 0.1504 \\
\hline 4 & 4 & 1.3406 & 8 & 0.1033 & 4 & 0.9517 \\
\hline 5 & 4 & 0.8646 & 4 & 1.6098 & 5 & 0.3587 \\
\hline 6 & 4 & 0.4290 & 4 & 0.5500 & 4 & 1.0092 \\
\hline $\begin{array}{ll}\begin{array}{l}\text { Maximum } \\
\text { coefficient in dB }\end{array} & \text { reflection } \\
\end{array}$ & \multicolumn{2}{|l|}{-10.2835} & \multicolumn{2}{|l|}{-9.3841} & \multicolumn{2}{|l|}{-9.3679} \\
\hline Total thickness in mm & \multicolumn{2}{|l|}{4.1332} & \multicolumn{2}{|l|}{3.6464} & \multicolumn{2}{|l|}{3.6713} \\
\hline
\end{tabular}

Table -4: Comparative statistical analysis after 20 trials for the (Model 1)

\begin{tabular}{|l|l|l|l|l|}
\hline Algorithm & Best & Worst & Mean & Standard deviation \\
\hline BBO & -6.1504 & -5.9174 & -6.0381 & 0.0447 \\
\hline FPA & -5.7376 & -4.8058 & -5.2239 & 0.2489 \\
\hline ABC & -5.6966 & -4.5645 & -5.2172 & 0.2684 \\
\hline
\end{tabular}

Table -5: Parameters for microwave absorber (6 layers) design for oblique incidence $\left(45^{0}\right)$ TE polarization optimized for overall reflection coefficient only (Model 2)

\begin{tabular}{|c|c|c|c|c|c|c|}
\hline \multirow[b]{2}{*}{ Layer } & \multicolumn{2}{|l|}{ BBO } & \multicolumn{2}{|l|}{ FPA } & \multicolumn{2}{|l|}{ ABC } \\
\hline & $\begin{array}{l}\text { Material } \\
\text { No. }\end{array}$ & $\begin{array}{l}\text { Thickness in } \\
\text { mm }\end{array}$ & $\begin{array}{l}\text { Material } \\
\text { No. }\end{array}$ & $\begin{array}{l}\text { Thickness in } \\
\text { mm }\end{array}$ & $\begin{array}{l}\text { Material } \\
\text { No. }\end{array}$ & $\begin{array}{l}\text { Thickness in } \\
\text { mm }\end{array}$ \\
\hline 1 & 16 & 0.2381 & 16 & 0.2419 & 16 & 0.2582 \\
\hline 2 & 6 & 0.7058 & 6 & 1.5529 & 6 & 1.8008 \\
\hline 3 & 6 & 1.3697 & 14 & 0.4795 & 14 & 1.6236 \\
\hline 4 & 16 & 0.8225 & 4 & 1.2493 & 15 & 0.9604 \\
\hline 5 & 5 & 1.3354 & 1 & 0.6666 & 5 & 1.6358 \\
\hline 6 & 5 & 1.7972 & 5 & 1.7116 & 4 & 1.1107 \\
\hline $\begin{array}{ll}\text { Maximum } & \text { reflection } \\
\text { coefficient in dB } & \\
\end{array}$ & \multicolumn{2}{|l|}{-11.7975} & \multicolumn{2}{|l|}{-11.2483} & \multicolumn{2}{|l|}{-11.0166} \\
\hline Total thickness in mm & \multicolumn{2}{|l|}{6.2687} & \multicolumn{2}{|l|}{5.9018} & \multicolumn{2}{|l|}{7.3894} \\
\hline
\end{tabular}


Table -6: Comparative statistical analysis after 20 trials for the (Model 2)

\begin{tabular}{|l|l|l|l|l|}
\hline Algorithm & Best & Worst & Mean & Standard deviation \\
\hline BBO & -11.7975 & -10.0176 & -11.0960 & 0.5646 \\
\hline FPA & -11.2483 & -9.8952 & -10.6528 & 0.3813 \\
\hline ABC & -11.0166 & -9.4397 & -10.0585 & 0.3416 \\
\hline
\end{tabular}

Table -7: Parameters for microwave absorber (6 layers) design for oblique incidence $\left(45^{0}\right)$ TM polarization optimized for overall reflection coefficient and total thickness of the absorber (Model 3)

\begin{tabular}{|c|c|c|c|c|c|c|}
\hline \multirow[b]{2}{*}{ Layer } & \multicolumn{2}{|l|}{ BBO } & \multicolumn{2}{|l|}{ FPA } & \multicolumn{2}{|l|}{$\mathbf{A B C}$} \\
\hline & $\begin{array}{l}\text { Material } \\
\text { No. }\end{array}$ & $\begin{array}{l}\text { Thickness } \\
\text { in } \mathbf{~ m m}\end{array}$ & $\begin{array}{l}\text { Material } \\
\text { No. }\end{array}$ & $\begin{array}{l}\text { Thickness } \\
\text { in } \mathbf{~ m m ~}\end{array}$ & $\begin{array}{l}\text { Material } \\
\text { No. }\end{array}$ & $\begin{array}{l}\text { Thickness } \\
\text { in } \mathbf{~ m m}\end{array}$ \\
\hline 1 & 16 & 0.1030 & 16 & 0.1822 & 6 & 0.1833 \\
\hline 2 & 6 & 1.4443 & 6 & 0.2693 & 16 & 0.2242 \\
\hline 3 & 14 & 0.4268 & 6 & 0.8301 & 8 & 0.2721 \\
\hline 4 & 8 & 0.7368 & 13 & 0.6979 & 6 & 0.7863 \\
\hline 5 & 4 & 0.8402 & 4 & 1.5618 & 4 & 0.4257 \\
\hline 6 & 4 & 1.8436 & 4 & 0.8225 & 4 & 1.7376 \\
\hline $\begin{array}{l}\text { Maximum } \\
\text { Reflection } \\
\text { Coefficient in dB }\end{array}$ & \multicolumn{2}{|l|}{-30.2481} & \multicolumn{2}{|l|}{-20.5088} & \multicolumn{2}{|l|}{-20.7433} \\
\hline $\begin{array}{l}\text { Total thickness } \\
\text { in } \mathbf{~ m m}\end{array}$ & \multicolumn{2}{|l|}{5.3948} & \multicolumn{2}{|l|}{4.3638} & \multicolumn{2}{|l|}{3.6291} \\
\hline
\end{tabular}

Table -8: Comparative statistical analysis after 20 trials for the (Model 3)

\begin{tabular}{|l|l|l|l|l|}
\hline Algorithm & Best & Worst & Mean & Standard deviation \\
\hline BBO & -24.8533 & -16.4655 & -18.4980 & 1.9837 \\
\hline FPA & -16.1449 & -13.2480 & -14.6000 & 0.8345 \\
\hline ABC & -17.1142 & -14.2078 & -15.5004 & 0.8690 \\
\hline
\end{tabular}

Table -9: Parameters for microwave absorber (6layers) design for oblique incidence $\left(45^{0}\right) \mathrm{TM}$ polarization optimized for overall reflection coefficient only (Model 4)

\begin{tabular}{|l|l|l|l|l|l|l|}
\hline \multirow{2}{*}{ Layer } & \multicolumn{3}{|l|}{ BBO } & FPA & ABC \\
\cline { 2 - 7 } & $\begin{array}{l}\text { Material } \\
\text { No. }\end{array}$ & $\begin{array}{l}\text { Thickness } \\
\text { in mm }\end{array}$ & $\begin{array}{l}\text { Material } \\
\text { No. }\end{array}$ & $\begin{array}{l}\text { Thickness } \\
\text { in mm }\end{array}$ & $\begin{array}{l}\text { Material } \\
\text { No. }\end{array}$ & $\begin{array}{l}\text { Thickness } \\
\text { in mm }\end{array}$ \\
\hline 1 & 16 & 0.1716 & 6 & 0.7208 & 16 & 0.1977 \\
\hline 2 & 6 & 1.3317 & 16 & 0.2630 & 8 & 1.7055 \\
\hline 3 & 4 & 0.8141 & 6 & 1.1166 & 5 & 0.9524 \\
\hline 4 & 6 & 1.4537 & 4 & 0.8265 & 6 & 1.8200 \\
\hline 5 & 7 & 0.2564 & 7 & 0.9604 & 4 & 1.8384 \\
\hline 6 & 4 & 1.6368 & 4 & 1.6835 & 8 & 0.7691 \\
\hline $\begin{array}{l}\text { Maximum } \\
\text { Reflection } \\
\text { Coefficient in dB }\end{array}$ & -25.2583 & & -22.3404 & & -22.7686 & \\
\hline $\begin{array}{l}\text { Total thickness } \\
\text { in mm }\end{array}$ & 5.6643 & 5.5707 & & 7.2831 & \\
\hline
\end{tabular}

Table -10: Comparative statistical analysis after 20 trials for the (Model 4)

\begin{tabular}{|l|l|l|l|l|}
\hline Algorithm & Best & Worst & Mean & Standard deviation \\
\hline BBO & -25.2583 & -17.7643 & -22.4666 & 1.9788 \\
\hline FPA & -22.3404 & -18.1716 & -19.4410 & 1.1317 \\
\hline ABC & -22.7686 & -18.4334 & -19.8876 & 1.1233 \\
\hline
\end{tabular}


Table -11: Parameters for microwave absorber (6 layers) design for oblique incidence $\left(60^{\circ}\right)$ TE polarization optimized for overall reflection coefficient and total thickness of the absorber (Model 5)

\begin{tabular}{|l|l|l|l|l|l|l|}
\hline \multirow{3}{*}{ Layer } & \multicolumn{3}{|l|}{ BBO } & FPA & ABC & $\begin{array}{l}\text { Thickness in } \\
\text { mm }\end{array}$ \\
\cline { 2 - 8 } & $\begin{array}{l}\text { Material } \\
\text { No. }\end{array}$ & $\begin{array}{l}\text { Material } \\
\text { mm }\end{array}$ & $\begin{array}{l}\text { Na. } \\
\text { No. }\end{array}$ & $\begin{array}{l}\text { Thickness in } \\
\text { mm }\end{array}$ \\
\hline 1 & 16 & 0.3169 & 16 & 0.3237 & 16 & 0.3130 \\
\hline 2 & 6 & 0.7450 & 6 & 0.5223 & 6 & 0.5268 \\
\hline 3 & 5 & 0.3574 & 6 & 0.4647 & 7 & 0.3742 \\
\hline 4 & 5 & 0.5914 & 4 & 1.2836 & 4 & 1.3664 \\
\hline 5 & 4 & 1.5383 & 4 & 0.5331 & 3 & 0.2648 \\
\hline 6 & 4 & 0.1333 & 5 & 0.8065 & 4 & 0.9812 \\
\hline $\begin{array}{l}\text { Maximum } \\
\text { Coefficient in dB }\end{array}$ & -6.6375 & -6.6851 & & -6.5227 & \\
\hline Total thickness in mm & 3.6823 & 3.9339 & & 3.8264 \\
\hline
\end{tabular}

Table -12: Comparative statistical analysis after 20 trials for the (Model 5)

\begin{tabular}{|l|l|l|l|l|}
\hline Algorithm & Best & Worst & Mean & Standard deviation \\
\hline BBO & -2.9551 & -2.7778 & -2.9053 & 0.0457 \\
\hline FPA & -2.7513 & -2.0113 & -2.3090 & 0.1852 \\
\hline ABC & -2.6963 & -2.0615 & -2.3877 & 0.1837 \\
\hline
\end{tabular}

Table -13: Parameters for microwave absorber (6layers) design for oblique incidence $\left(60^{\circ}\right)$ TE polarization optimized for overall reflection coefficient only (Model 6)

\begin{tabular}{|l|l|l|l|l|l|l|}
\hline \multirow{3}{*}{ Layer } & \multicolumn{3}{|l|}{ BBO } & FPA & ABC \\
\cline { 2 - 8 } & $\begin{array}{l}\text { Material } \\
\text { No. }\end{array}$ & $\begin{array}{l}\text { Thickness in } \\
\text { mm }\end{array}$ & $\begin{array}{l}\text { Material } \\
\text { No. }\end{array}$ & $\begin{array}{l}\text { Thickness in } \\
\text { mm }\end{array}$ & $\begin{array}{l}\text { Material } \\
\text { No. }\end{array}$ & $\begin{array}{l}\text { Thickness in } \\
\text { mm }\end{array}$ \\
\hline 1 & 16 & 0.2586 & 16 & 0.2695 & 16 & 0.2594 \\
\hline 2 & 6 & 1.9907 & 6 & 1.8572 & 6 & 1.8987 \\
\hline 3 & 16 & 0.8464 & 15 & 0.9149 & 16 & 1.4822 \\
\hline 4 & 5 & 1.7802 & 5 & 1.5704 & 5 & 1.5316 \\
\hline 5 & 7 & 1.9986 & 6 & 1.6678 & 5 & 1.6458 \\
\hline 6 & 3 & 1.9084 & 4 & 1.6473 & 15 & 0.2093 \\
\hline $\begin{array}{l}\text { Maximum } \\
\text { Coefficient in dB }\end{array}$ & -7.0960 & -7.7165 & & -7.7166 & \\
\hline Total thickness in mm & 8.7828 & 7.9272 & & 7.0271 \\
\hline
\end{tabular}

Table -14: Comparative statistical analysis after 20 trials for the (Model 6)

\begin{tabular}{|l|l|l|l|l|}
\hline Algorithm & Best & Worst & Mean & Standard deviation \\
\hline BBO & -8.0960 & -7.1832 & -7.6399 & 0.2834 \\
\hline FPA & -7.7165 & -6.8083 & -7.2663 & 0.2062 \\
\hline ABC & -7.7166 & -6.6386 & -7.1055 & 0.3185 \\
\hline
\end{tabular}

Table -15: Parameters for microwave absorber (6 layers) design for oblique incidence $\left(60^{\circ}\right)$ TM polarization optimized for overall reflection coefficient and total thickness of the absorber (Model 7)

\begin{tabular}{|c|c|c|c|c|c|c|}
\hline \multirow[b]{2}{*}{ Layer } & \multicolumn{2}{|l|}{ BBO } & \multicolumn{2}{|l|}{ FPA } & \multicolumn{2}{|l|}{$\mathbf{A B C}$} \\
\hline & $\begin{array}{l}\text { Material } \\
\text { No. }\end{array}$ & $\begin{array}{l}\text { Thickness in } \\
\text { mm }\end{array}$ & $\begin{array}{l}\text { Material } \\
\text { No. }\end{array}$ & $\begin{array}{l}\text { Thickness in } \\
\text { mm }\end{array}$ & $\begin{array}{l}\text { Material } \\
\text { No. }\end{array}$ & $\begin{array}{l}\text { Thickness in } \\
\text { mm }\end{array}$ \\
\hline 1 & 6 & 0.4691 & 6 & 0.2284 & 7 & 1.1456 \\
\hline 2 & 8 & 1.0507 & 16 & 0.2784 & 13 & 0.3219 \\
\hline 3 & 16 & 0.1029 & 2 & 0.5625 & 8 & 0.6492 \\
\hline 4 & 4 & 0.3186 & 7 & 0.7283 & 6 & 1.5346 \\
\hline 5 & 7 & 1.6255 & 6 & 0.4981 & 4 & 1.2964 \\
\hline 6 & 4 & 1.5732 & 4 & 1.7882 & 4 & 0.4982 \\
\hline $\begin{array}{ll}\text { Maximum } & \text { Reflection } \\
\text { Coefficient in dB }\end{array}$ & \multicolumn{2}{|l|}{-33.7700} & \multicolumn{2}{|l|}{-25.2479} & \multicolumn{2}{|l|}{-27.5844} \\
\hline Total thickness in mm & \multicolumn{2}{|l|}{5.1399} & \multicolumn{2}{|l|}{4.0839} & \multicolumn{2}{|l|}{5.4458} \\
\hline
\end{tabular}


Table -16: Comparative statistical analysis after 20 trials for the (Model 7)

\begin{tabular}{|l|l|l|l|l|}
\hline Algorithm & Best & Worst & Mean & Standard deviation \\
\hline BBO & -28.6300 & -18.3061 & -22.1693 & 2.4139 \\
\hline FPA & -21.1640 & -16.1706 & -19.0248 & 1.4408 \\
\hline ABC & -22.1386 & -17.1725 & -19.0996 & 1.3767 \\
\hline
\end{tabular}

Table -17: Parameters for microwave absorber (6layers) design for oblique incidence $\left(60^{0}\right) \mathrm{TM}$ polarization optimized for overall reflection coefficient only (Model 8)

\begin{tabular}{|l|l|l|l|l|l|l|}
\hline \multirow{3}{*}{ Layer } & BBO & FPA & ABC \\
\cline { 2 - 7 } & $\begin{array}{l}\text { Material } \\
\text { No. }\end{array}$ & $\begin{array}{l}\text { Thickness in } \\
\text { mm }\end{array}$ & $\begin{array}{l}\text { Material } \\
\text { No. }\end{array}$ & $\begin{array}{l}\text { Thickness in } \\
\text { mm }\end{array}$ & $\begin{array}{l}\text { Material } \\
\text { No. }\end{array}$ & $\begin{array}{l}\text { Thickness in } \\
\text { mm }\end{array}$ \\
\hline 1 & 7 & 1.0262 & 8 & 0.3949 & 7 & 1.3312 \\
\hline 2 & 15 & 0.4465 & 7 & 1.1760 & 14 & 0.3600 \\
\hline 3 & 8 & 0.5817 & 13 & 0.3822 & 8 & 1.8722 \\
\hline 4 & 2 & 0.5536 & 6 & 1.3205 & 12 & 1.0538 \\
\hline 5 & 8 & 1.4546 & 7 & 1.4054 & 7 & 0.8118 \\
\hline 6 & 4 & 1.8593 & 4 & 1.8743 & 4 & 1.7605 \\
\hline $\begin{array}{l}\text { Maximum } \\
\text { Coefficient in dB Reflection }\end{array}$ & -36.6882 & -26.9362 & & -26.8151 \\
\hline Total thickness in mm & 5.9219 & 6.5533 & & 7.1895 \\
\hline
\end{tabular}

Table -18: Comparative statistical analysis after 20 trials for the (Model 8)

\begin{tabular}{|l|l|l|l|l|}
\hline Algorithm & Best & Worst & Mean & Standard deviation \\
\hline BBO & -36.6882 & -24.3533 & -28.7182 & 3.0840 \\
\hline FPA & -26.9362 & -23.4013 & -24.8761 & 0.7969 \\
\hline ABC & -26.8151 & -22.3841 & -24.9769 & 1.0747 \\
\hline
\end{tabular}

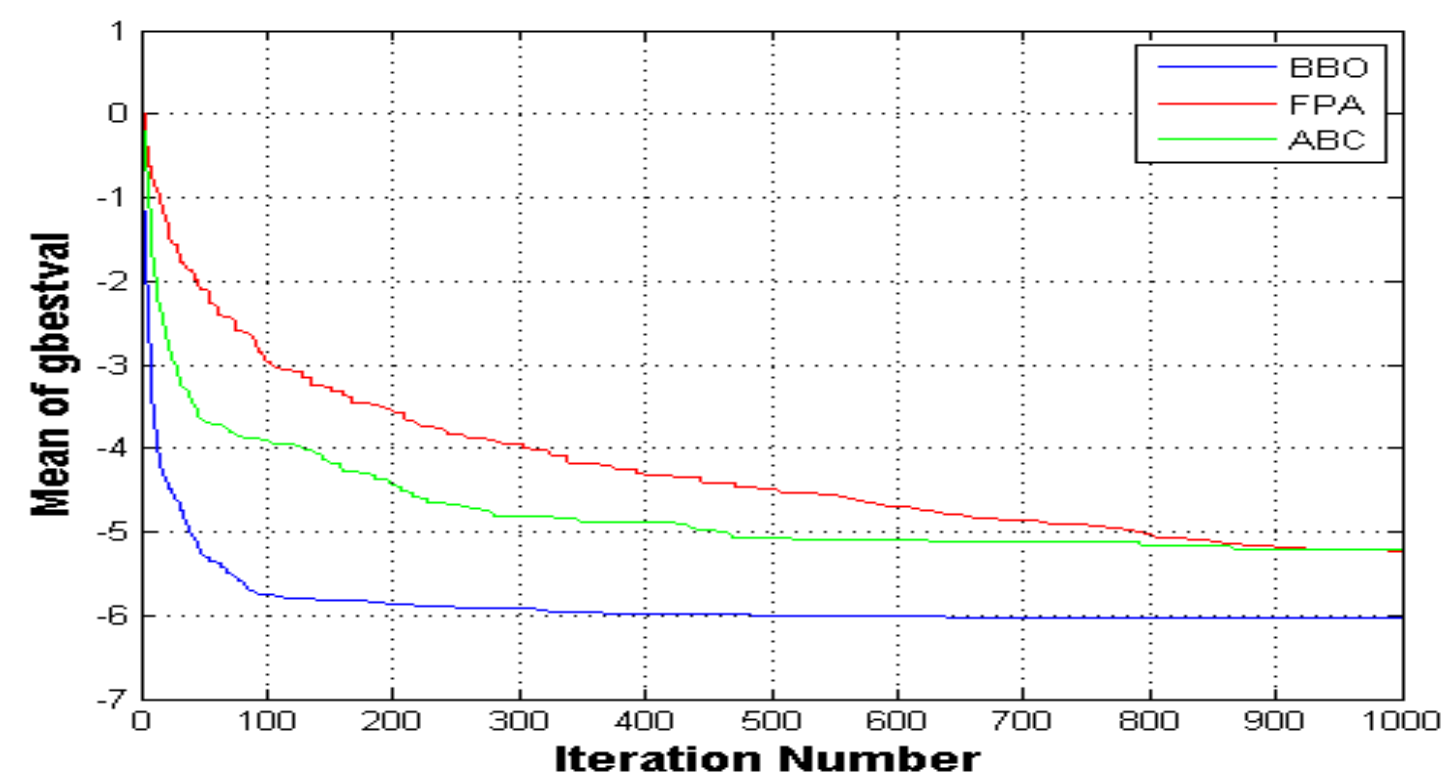

Fig -11: Mean of best fitness value versus iteration (Model 1) 


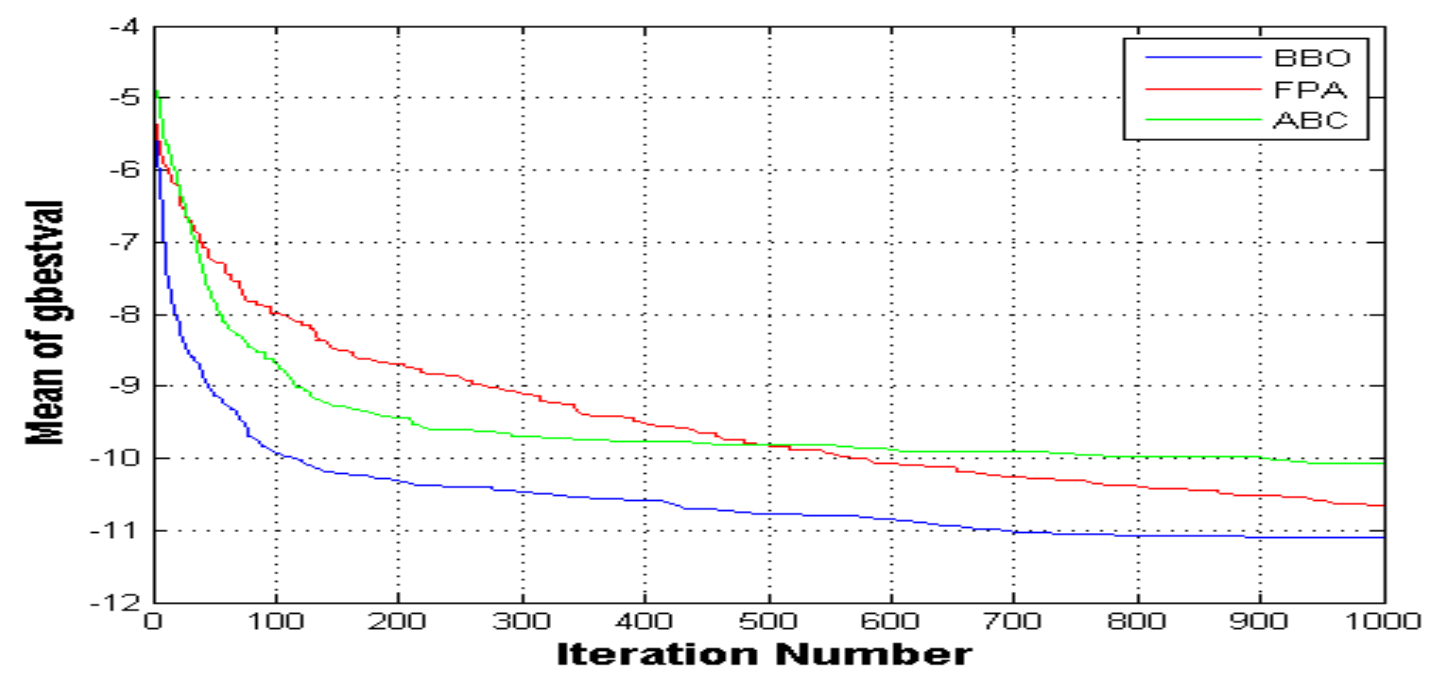

Fig -12: Mean of best fitness value versus iteration (Model 2)

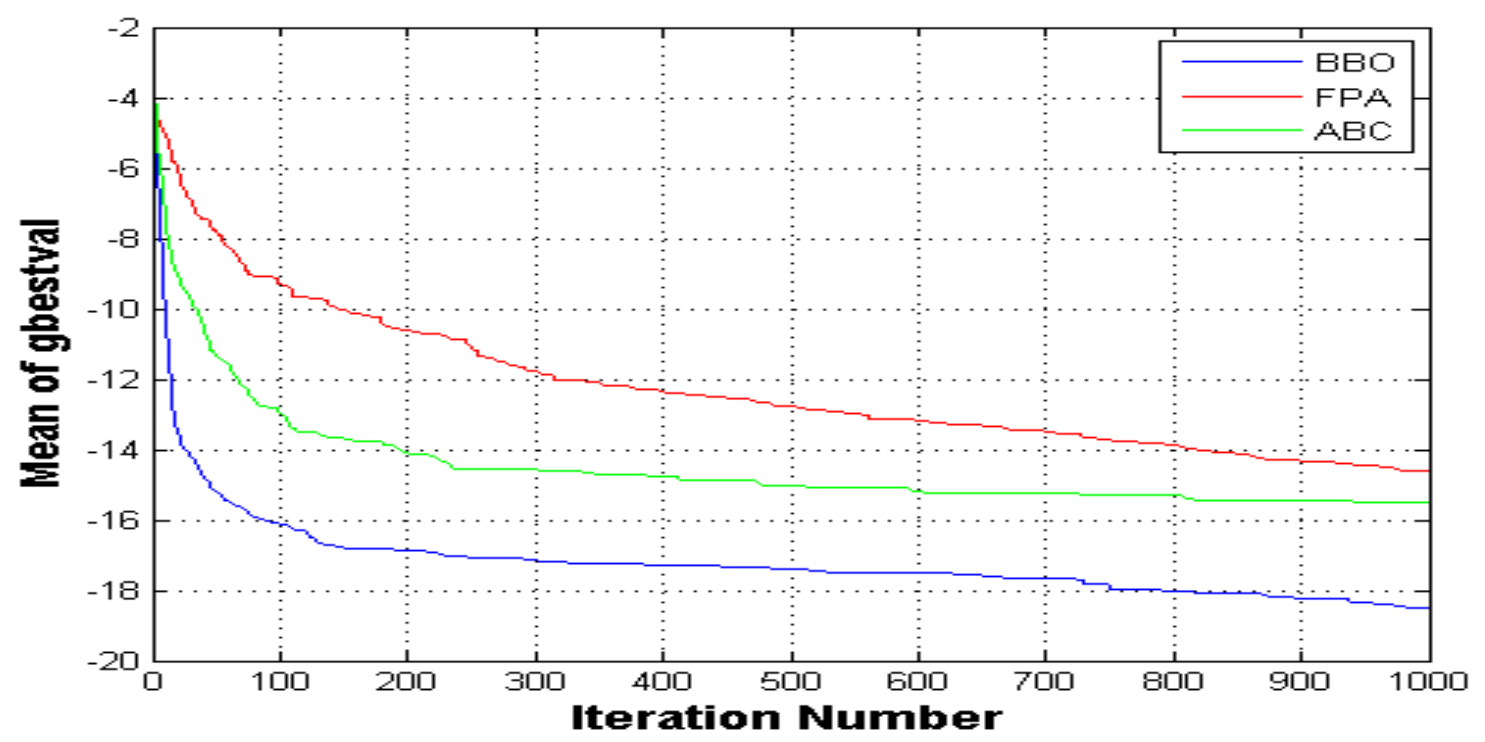

Fig -13: Mean of best fitness value versus iteration (Model 3)

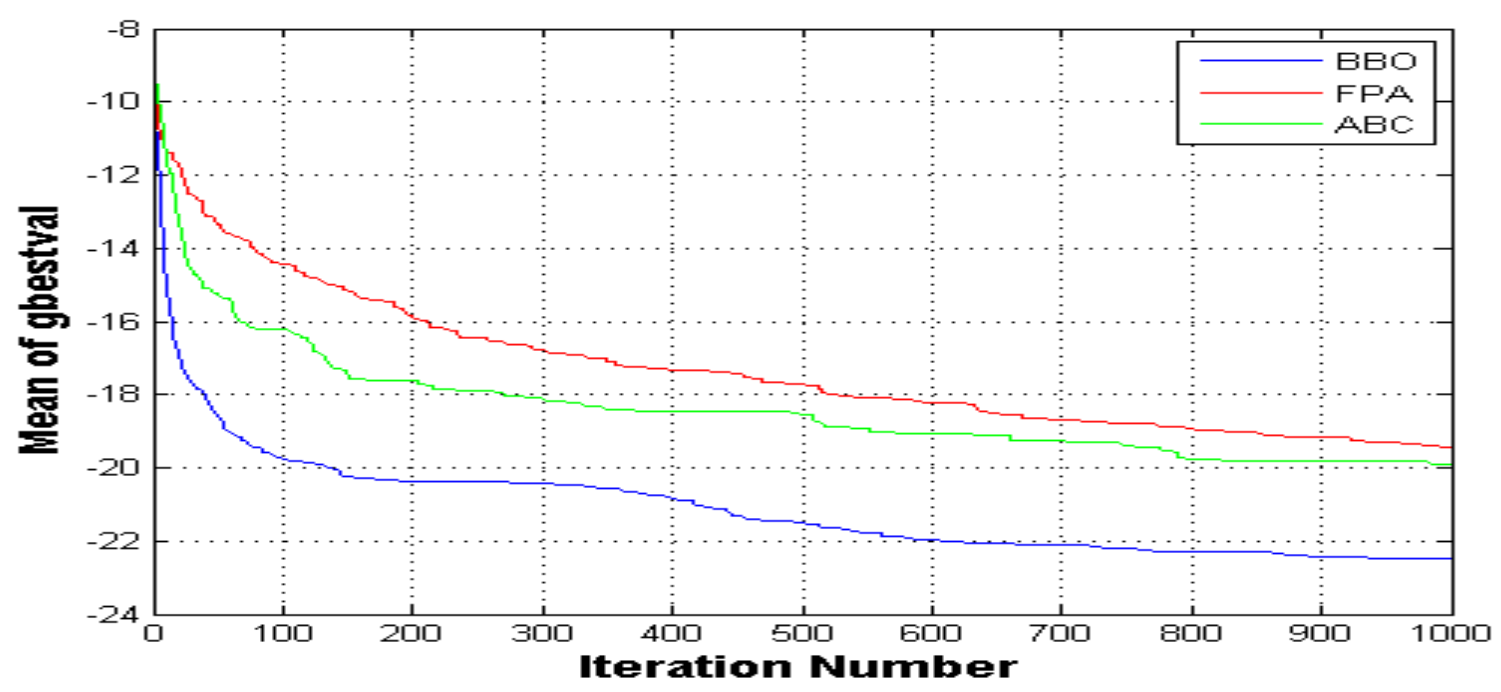

Fig -14: Mean of best fitness value versus iteration (Model 4) 


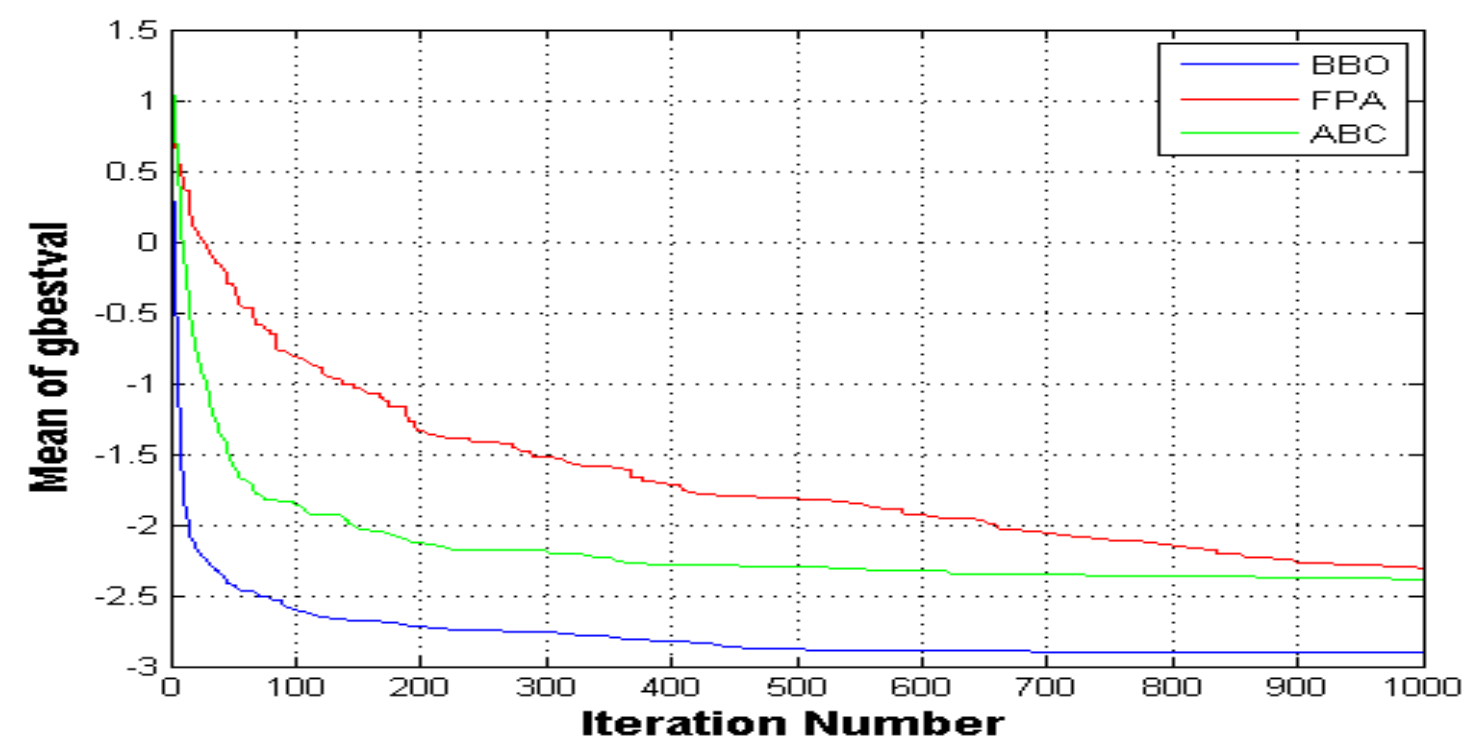

Fig -15: Mean of best fitness value versus iteration (Model 5)

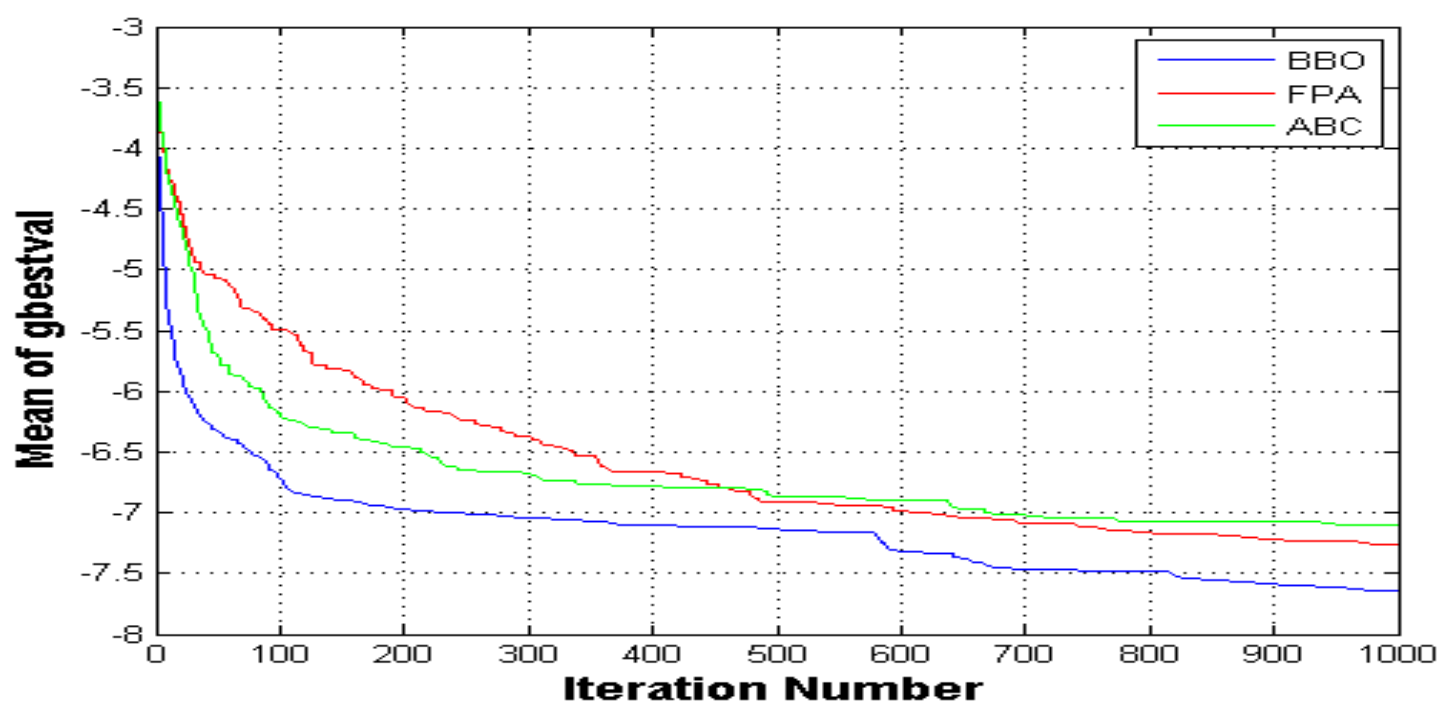

Fig -16: Mean of best fitness value versus iteration (Model 6)

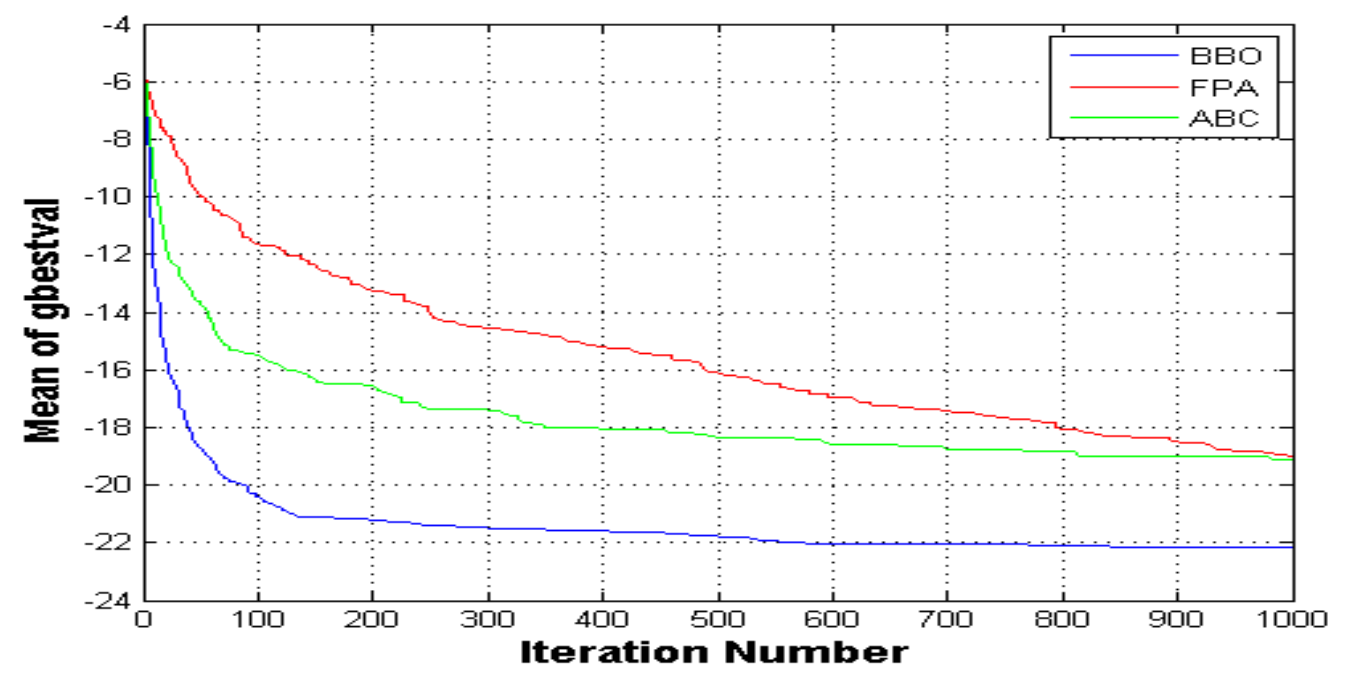

Fig -17: Mean of best fitness value versus iteration (Model 7) 


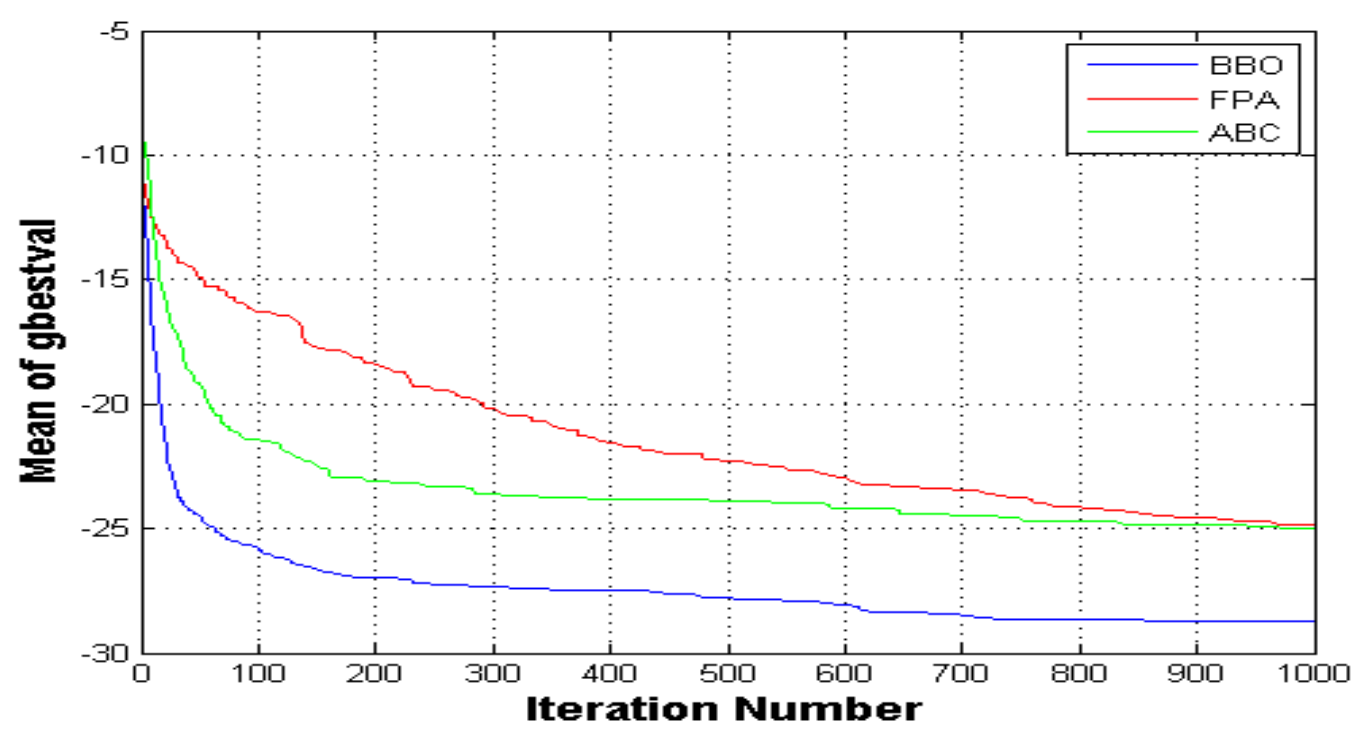

Fig -18: Mean of best fitness value versus iteration (Model 8)

\section{CONCLUSION}

The application of swarm based nature inspired optimization algorithms namely Biogeography based optimization algorithm (BBO), Flower pollination algorithm (FPA) and Artificial bee colony optimization algorithm(ABC) for synthesizing wideband multilayer microwave absorber has been presented in this paper. The optimization has been carried out for oblique wide angle $\left(45^{\circ}, 60^{\circ}\right)$ of incidence taking arbitrary polarization of the electromagnetic wave. The comparative performance of $\mathrm{BBO}, \mathrm{FPA}$ and $\mathrm{ABC}$ for the optimum design of 8 different models of microwave absorber has been presented. The study clearly established the effectiveness of our proposed design for solving the proper tradeoff between two very important conflicting parameters such as overall reflection coefficient and total thickness of the multilayer microwave absorber while designing the same. It has also been traced out in this paper that for normal incidence as both TE and TM yield the same magnitude of the reflection coefficient hence it is required to set the reflection coefficient between the PEC $\left(\boldsymbol{R}_{N, N+1}\right)$ and the last layer of the multilayer structure to +1 for $\mathrm{TM}$ polarization and to -1 for TE polarization of the electromagnetic wave which blatantly neglected in many papers deals with the same problem.

\section{REFERENCES}

[1]. Eric Michielssen, Jean-Michel Sajer, S. Ranjithan, and Raj Mittra, "Design of lightweight, broad-band microwave absorbers using genetic algorithms," IEEE Trans. on Microwave Theory and Techniques, Vol. 41, No. 6/7, 10241031, June/July 1993.

[2]. Weile, D., E. Michielssen, and D. Goldberg, "Genetic algorithm design of pareto optimal broadband microwave absorbers," IEEE Trans. on Electromagnetic Compatibility, Vol. 38, No.3, 518-525, August 1996.
[3]. Macedo, J., M.de Sousa, and V. Dmitriev, Optimization of wideband multilayer microwave absorbers for any angle of incidence and arbitrary polarization,

"International conference on Microwave and Optoelectronics”, 558-561, Brasilia, Brazil, 2005.

[4]. S. Chamaani, S. A. Mirtaheri, M. Teshnehlab, M. A. Shoorehdeli and V. Seydi, "Modified multi-objective particle swarm optimization for electromagnetic absorber design," Progress In Electromagnetics Research, Vol. 79, 353-366, 2008.

[5]. Chamaani, S., S. Mirtaheri, and M. Shooredeli, "Design of very thin wide band absorbers using modified local best particle swarm optimization," AEU- Int. J. Electron. Commun, Vol. 62, 549-556, 2008.

[6]. L. Jiang, J. Cui, L. Shi, X. Li, "Pareto optimal design of multilayer microwave absorbers for wide-angle incidence using genetic algorithms", IET Microwaves, Antennas \& Propagation, Vol. 3,Iss. 4, pp. 572-579, 2009.

[7]. M. J. Asi and N. I. Dib, "Design of multilayer microwave broadband absorbers using central force optimization," Progress In Electromagnetics Research B, Vol. 26, 101-113, 2010.

[8]. N. Dib, M. Asi, and A. Sabbah, "On the optimal design of multilayer microwave absorbers," Progress In Electromagnetics Research C, Vol. 13, 171-185, 2010.

[9]. Chew, W. C., Waves and Fields in Inhomogeneous Media, IEEE Press, New York, 1995.

[10]. L. Jiang J. Cui L. Shi X. Li, "Pareto optimal design of multilayer microwave absorbers for wide-angle incidence using genetic algorithms", IET Microwave, Antennas \& Propagation., Vol. 3, Iss. 4, pp. 572-579, 2009.

[11]. Goudos, S., "Design of microwave broadband absorbers using a self-adaptive differential evolution algorithm," Int. J. RF and Microwave CAE, Vol. 19, pp.364-372, May 2009.

[12]. Michielssen, E., J. Sajer, S. Ranjithan, and R. Mittra, "Design of lightweight, broad-band microwave absorbers using genetic algorithms," IEEE Trans. on Microwave 
Theory and Techniques, Vol. 41, No. 6/7, pp.1024-1031, June/July 1993.

[13]. L. Jiang J. Cui L. Shi X. Li, "Pareto optimal design of multilayer microwave absorbers for wide-angle incidence using genetic algorithms", IET Microwave, Antennas\& Propagation., Vol. 3, Iss. 4, pp. 572-579, 2009.

[14]. J. Kennedy and R. C. Eberhart, "Particle swarm optimization," Proc. IEEE Int. Conf. Neural Networks, pp. 1942-1948, Perth, Australia, 1995.

[15]. W. T. Li, X. W. Shi and Y. Q. Hei, "An Improved Particle Swarm Optimization Algorithm for Pattern Synthesis of Phased Arrays," Progress In Electromagnetics Research, Vol. 82, pp.319-332, 2008.

[16]. J. Robinson, and Y. Rahmat-Samii, "Particle swarm optimization in electromagnetics," IEEE Transactions on Antennas and Propagation, Vol. 52, No. 2, pp.397-407, February 2004.

[17]. N. Jin and Y. Rahmat-Samii, "Advances in particle swarm optimization for antenna designs: Real-number, binary, single- objective and multi objective implementations," IEEE Transactions on Antennas and Propagation. Vol. 55, no. 3, pp.556-567, March 2007.

[18]. T. B. Chen, Y. L. Dong, Y. C. Jiao, and F. S. Zhang, "Synthesis of circular antenna array using crossed particle swarm optimization algorithm," Journal of Electromagnetic Waves and Appl., Vol. 20, No. 13, pp.1785-1795, 2006.

[19]. D. W. Boeringer, and D. H.Werner, "Particle swarm optimization versus genetic algorithms for phased array synthesis," IEEE Transactions on Antennas and Propagation, Vol. 52, No. 3, pp.771-779, 2004.

[20]. Bansal, J. C., P. K. Singh, Mukesh Saraswat, AbhishekVerma, Shimpi Singh Jadon, and Ajith Abraham. "Inertia weight strategies in particle swarm optimization." IEEE Third World Congress on Nature and Biologically Inspired Computing (NaBIC), Salamanca, Spain, pp. 633640, 2011.

[21]. Liang,J. J., and PonnuthuraiNagaratnamSuganthan. "Dynamic multi-swarm particle swarm optimizer." Proceedings IEEE Swarm Intelligence Symposium, 124-129, Pasadena, California, SIS 2005.

[22]. K. R. Mahmoud, M. I. Eladawy, R. Bansal, S. H. Zainud-Deen, and S. M. M. Ibrahem, "Analysis of uniform circular arrays for adaptive beamforming applications using particle swarm optimization algorithm," International Journal of $R F$ and Microwave Computer-Aided Engineering, vol. 18, no. 1, pp. 42-52, January 2008.

[23]. Urvinder Singh, Harish Kumar and Tara Singh Kamal, "Design of Yagi-Uda Antenna Using Biogeography Based Optimization," IEEE Transactions on Antennas and Propagation, Vol.58, No.10, pp.3375-3379, October 2010.

[24]. U Singh, T.S.Kamal, "Synthesis of thinned planar concentric circular antenna arrays using biogeography-based optimization," IET Microw. Antennas Propag., Vol. 6, Iss. 7, pp. 822-829, 2012.

[25]. Dan Simon, "Biogeography-Based Optimization," IEEE Trans. on Evolutionary Computation, Vol.12, No.6. December 2008.

[26]. N. Sakib, Md. Wasi UI Kabir, Md Subbir, Mohammad Shafiul Alam, "A Comparative Study of Flower Pollination Algorithm and Bat Algorithm on Continuous Optimization
Problems," International Journal of Applied Information Systems, Vol.7, No.9, September 2014.

[27]. Karaboga, D., Basturk, B., and "Artificial bee colony (ABC) optimization algorithm for solving constrained optimization problems, In LNCS: Advances in Soft Computing: Foundations of Fuzzy Logic and Soft Computing, Springer-Verlag, vol. 4529, 789-798, 2007.

[28]. Karaboga, D.; Basturk, B.: A powerful and efficient algorithm for numerical function optimization: artificial bee colony (ABC) algorithm. J. Global Optim., 39 (3) , 459471, 2007.

\section{BIOGRAPHIES}

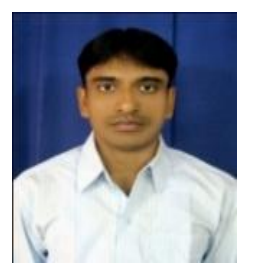

JyotirmayTewary received his Bachelor of Engineering (B.E) degree in Electronics \& Telecommunication Engineering from Amravati University Maharashtra, India and M.Tech from National Institute of Technology Durgapur, India. Presently he is working towards his $\mathrm{PhD}$ in Electronics \& Communication Engineering from National Institute of Technology Durgapur, India.

\section{Email:tewaryjyotirmay@gmail.com}

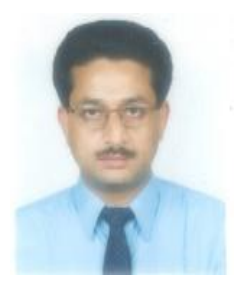

G.K.Mahanti was born in the year 1967 in West Bengal, India. He obtained his B.E. in Electronics \& Communication Engg. from NIT, Durgapur, India, M.E. in Electronics System and Communication from NIT, Rourkela, India and Ph.D(Engg.) from IIT, Kharagpur, India. He has more than 20 years of teaching and research experience. Presently he is working as Professor, department of Electronics and Communication Engineering, National Institute of Technology, Durgapur, India. He is a senior member of IEEE, USA. His research area is Array antenna synthesis, Evolutionary Algorithms \&Electromagnetics.

\section{Email:gautammahanti@yahoo.com}

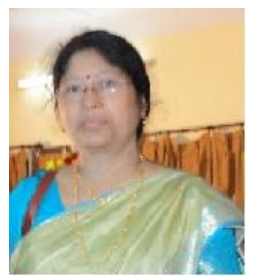

KajlaBasu completed her M.Sc and $\mathrm{Ph} . \mathrm{D}$ degree in Mathematics from IIT,Kharagpur.She has published 40 papers in international \& national journals and conference proceedings. She is presently a professor in the department of Mathematics,NIT, Durgapur. She was also former head of the department of Mathematics. Her research area is operation research and statistical analysis.

Email:kajla.basu@gmail.com 